\title{
A Conceptual Model of Investor Behavior
}

\author{
Milan Lovric, Uzay Kaymak and Jaap Spronk
}

\begin{tabular}{|l|l|}
\hline \multicolumn{2}{|l|}{ ERIM REPORT SERIES RESEARCH IN MANAGEMENT } \\
\hline ERIM Report Series reference number & ERS-2008-030-F\&A \\
\hline Publication & May 2008 \\
\hline Number of pages & 52 \\
\hline Persistent paper URL & http://hdl.handle.net/1765/12468 \\
\hline Email address corresponding author & lovric@few.eur.nl \\
\hline Address & Erasmus Research Institute of Management (ERIM) \\
& RSM Erasmus University / Erasmus School of Economics \\
& Erasmus Universiteit Rotterdam \\
& P.O.Box 1738 \\
& 3000 DR Rotterdam, The Netherlands \\
& Phone: + 31 10 408 1182 \\
& Fax: + 3110 408 9640 \\
& Email: info@erim.eur.nl \\
& Internet: www.erim.eur.nl \\
\hline
\end{tabular}

Bibliographic data and classifications of all the ERIM reports are also available on the ERIM website: www.erim.eur.nl 


\section{ERASMUS RESEARCH INSTITUTE OF MANAGEMENT}

\section{REPORT SERIES \\ RESEARCH IN MANAGEMENT}

\begin{tabular}{|l|l|}
\hline ABSTRACT AND KEYWORDS \\
\hline Abstract & $\begin{array}{l}\text { Based on a survey of behavioral finance literature, this paper presents a descriptive model of } \\
\text { individual investor behavior in which investment decisions are seen as an iterative process of } \\
\text { interactions between the investor and the investment environment. This investment process is } \\
\text { influenced by a number of interdependent variables and driven by dual mental systems, the } \\
\text { interplay of which contributes to boundedly rational behavior where investors use various } \\
\text { heuristics and may exhibit behavioral biases. In the modeling tradition of cognitive science and } \\
\text { intelligent systems, the investor is seen as a learning, adapting, and evolving entity that } \\
\text { perceives the environment, processes information, acts upon it, and updates his or her internal } \\
\text { states. This conceptual model can be used to build stylized representations of (classes of) } \\
\text { individual investors, and further studied using the paradigm of agent-based artificial financial } \\
\text { markets. By allowing us to implement individual investor behavior, to choose various market } \\
\text { mechanisms, and to analyze the obtained asset prices, agent-based models can bridge the gap } \\
\text { between the micro level of individual investor behavior and the macro level of aggregate market } \\
\text { phenomena. It has been recognized, yet not fully explored, that these models could be used as a } \\
\text { tool to generate or test various behavioral hypothesis. }\end{array}$ \\
\hline investor behavior, financial decision making, behavioral finance, cognitive modeling, agent- \\
based artificial financial markets
\end{tabular}




\title{
A CONCEPTUAL MODEL OF INVESTOR BEHAVIOR
}

\author{
MILAN LOVRIC \\ UZAY KAYMAK \\ Draft, May 2008 \\ MILAN LOVRIC \\ Department of Finance, Erasmus School of Economics, \\ Erasmus University Rotterdam, Burgemeester Oudlaan 50 \\ P.O. Box 1738, 3000DR Rotterdam, The Netherlands \\ lovric@few.eur.nl \\ UZAY KAYMAK \\ Department of Econometrics, Erasmus School of Economics, \\ Erasmus University Rotterdam, Burgemeester Oudlaan 50 \\ P.O. Box 1738, 3000DR Rotterdam, The Netherlands \\ kaymak@few.eur.nl \\ JAAP SPRONK \\ Department of Finance, Erasmus School of Economics, \\ Erasmus University Rotterdam, Burgemeester Oudlaan 50 \\ P.O. Box 1738, 3000DR Rotterdam, The Netherlands \\ spronk@few.eur.nl
}

JAAP SPRONK

\begin{abstract}
Based on a survey of behavioral finance literature, this paper presents a descriptive model of individual investor behavior in which investment decisions are seen as an iterative process of interactions between the investor and the investment environment. This investment process is influenced by a number of interdependent variables and driven by dual mental systems, the interplay of which contributes to boundedly rational behavior where investors use various heuristics and may exhibit behavioral biases. In the modeling tradition of cognitive science and intelligent systems, the investor is seen as a learning, adapting, and evolving entity that perceives the environment, processes information, acts upon it, and updates his or her internal states. This conceptual model can be used to build stylized representations of (classes of) individual investors, and further studied using the paradigm of agent-based artificial financial markets. By allowing us to implement individual investor behavior, to choose various market mechanisms, and to analyze the obtained asset prices, agent-based models can bridge the gap between the micro level of individual investor behavior and the macro level of aggregate market phenomena. It has been recognized, yet not fully explored, that these models could be used as a tool to generate or test various behavioral hypothesis.
\end{abstract}

\section{Keywords}

investor behavior, financial decision making, behavioral finance, cognitive modeling, agentbased artificial financial markets 


\section{Introduction}

This paper presents a conceptual model of the individual investor. By taking a descriptive point of view, we focus our attention on how investors make their investment decisions in a real world setting, as opposed to rational/optimal behavior proposed by normative financial theories. This conceptual model incorporates results of the research on investment decisions from fields of behavioral finance and cognitive psychology. It is based on a review of existing studies, which themselves were conducted using various research methods. It particularly draws on the heuristics and biases strand of behavioral finance literature, as well as the dual-process theories of human cognition.

In the rapidly growing field of behavioral finance it becomes more difficult to devise a unifying taxonomy of all the behavioral phenomena, as they arise from various mechanisms, manifest on different levels of behavior and cognition, and have been discovered using various methodologies (e.g. experiments vs. quantitative analysis of market data). However, a conceptual model that presents some of the most important findings from the existing research on investor behavior, and provides a parsimonious description of how individual investors make their investment/trading decisions is relevant from both a theoretical and a practical point of view.

The main motivation for building this conceptual model is that on the basis of this conceptual model a computational model of the individual investor (or stylized classes of various market participants) can be implemented, and then further studied using the paradigm of agent-based artificial financial markets.

An interesting bottom-up approach for studying economies has recently become known as agent-based computational economics (ACE) - the computational study of economies modeled as evolving systems of autonomous interacting agents (Tesfatsion and Judd, 2006). ACE researchers use computational laboratories to study the evolution of decentralized market economies under controlled experimental conditions. The construction of economy starts with an initial population of agents - both economic agents (e.g. traders, financial institutions,...) and socioenvironmental agents (e.g., government, land, weather,...). The initial state of the economy is specified as initial attributes of the agents (type characteristics, internalized behavioral norms, internal modes of behavior (including modes of communication and learning), and internally stored information about itself and other agents). The economy then evolves over time and arises from agent interactions, without further intervention from the modeler (Tesfatsion and Judd, 2006)

Similar approach to studying and understanding stock markets is adopted in the area of 
computational finance as artificial stock markets (or, more generally, artificial financial markets). An artificial stock market (ASM) is, like any other model, an external and explicit representation of a part of reality (that are stock markets) as seen by the people who wish to use that model to understand, to change, to manage and to control the part of reality (Boer-Sorban et al., 2005; Pidd, 2000). Agent-based artificial stock markets are artificial markets where participants are represented as individual software components (Boer-Sorban et al., 2005)

Agent-based artificial financial markets can be mathematical or computational models of financial markets, usually comprised of a number of heterogeneous and boundedly rational agents, which interact through some trading mechanism, while possibly learning and evolving. These models are built for the purpose of studying agents' behavior, price discovery mechanisms, the influence of market microstructure, the reproduction of the stylized facts of real-world financial time-series (e.g. fat tails of return distributions and volatility clustering). A number of reviews of studies with artificial financial markets are available, e.g. for computational models (LeBaron, 2006), and for mathematical models (Hommes, 2006).

Analogous methodology to agent-based modeling comes from the physical sciences, namely the Macroscopic Simulation. This methodology is a tool for studying complex systems by simulating many interacting microscopic elements, and has been also applied to financial markets by Levy et al. (2000). They believe that Microscopic Simulation models could be used to extend existing analytical models in finance by inspecting the role of their assumptions, or to build new models that could be as realistic as desired, e.g. models that incorporate various technical and fundamental strategies observed in experiments and real markets; dynamic models with heterogeneous investors that can learn and change strategies.

Despite many studies with artificial financial markets, not much attempt has been made to incorporate complex behavioral phenomena into agents' behavior. These attempts may have been hindered by multiple reasons. For instance, complex behavior implies highly parameterized models which are difficult to examine and that often lie beyond analytical tractability. Some studies implement very simple behavior (e.g. zero-intelligence with budget constraints (Gode and Sunder, 1993)) as they want to put more emphasis on other issues, such as the market microstructure. Sometimes it is interesting to examine what kind of complexity can emerge from very simple behavior, with the addition of some heterogeneity, interaction, and/or learning. The famous spatial proximity model (Schelling, 1978) is an example of agent-based work where unexpected aggregate pattern of segregation appears even though it was not coded as such on the microlevel. Sugarscape model (Epstein and Axtell, 1996) is another example of a simple 
local behavior that leads to interesting macro patterns. Furthermore, a descriptive approach to investor behavior is at odds with a traditional, mainstream view in economics and finance that relies on the assumption of (as-if) rationality, which is often exemplified by Milton Friedman's positivist arguments (Friedman, 1984).

However, an agent-based approach inspires us to seek for homeomorphic models (Harré, 1970), that not only reproduce the stylized facts of real-world markets, but also achieve them through processes that are grounded on reasonable (psychologically plausible) assumptions, and resemble actual human behavior and realistic market mechanisms. Agent-based models can easily accommodate complex learning behavior, asymmetric information, heterogeneous preferences, and ad hoc heuristics (Chan et al., 1999). It is far from the fact that everything is known about human behavior and cognition pertaining to the investment decisions, but as various fields progress to open up these black boxes, a methodology that can utilize such knowledge may be given more opportunities in the future.

The purpose of this paper is to give a structured and unifying look on the existing research on investor behavior, asking ourselves what we currently know about individual investors and how they make investment/trading decisions. The conceptual model is proposed having in mind an agent-based modeler of financial markets who is striving for a more realistic representation of agent behavior than what can be found in the existing agent-based research. A computational model that implements such a rich behavior would be a contribution to computational finance literature (on agent-based financial markets) not only on the level of reached complexity of individual agents, but also through the departure from bounded rationality approach to a stronger behavioral approach that encompasses relevant findings from behavioral finance literature and psychology. The complementarity of behavioral finance research and the agent-based methodology has not yet been explored, as explained by on of the leading researchers in the area of agent-based financial markets: "Up to this point very little reference has been made to the growing literature on behavioral finance. It is important to define where agent-based financial markets sit relative to this larger field. First, they are clearly behavioral models themselves, since the agents are boundedly rational and follow simple rules of thumb. This is a key characteristics of any behavioral model, and agent-based models have this characteristics. Where agent-based financial market models have diverged to date from behavioral finance models is their typical presumption that agent preferences have relatively standard representations. Typically, no attempt is made to model common behavioral biases such as loos aversion or hyperbolic discounting. This is not because agent-based models cannot handle these behavioral aspects, Rather, it has just seemed 
sensible in this early stage of the field to refrain from adding too many more complications to models which are already very complicated. It is important to note that agent-based technologies are well suited for testing behavioral theories. They can answer two key questions that should be asked of any behavioral structure. First, how well do behavioral biases hold up under aggregation, and second which types of biases will survive in a coevolutionary struggle against others. Therefore, the connections between agent-based approaches and behavioral approaches will probably become more intertwined as both fields progress" (LeBaron, 2006) ${ }^{1}$.

Further motivation for this paper we also found in (Chen and Liao, 2003): "It is the learning, adapting and evolving abilities that we give to our agents in the agent-based models that can deal with some issues which complement the neoclassical and behavioral approaches. Instead of extraneously imposing a specific kind of behavioral bias, e.g., overconfidence or conservatism, on the agents, we can canvass the emergence and/or the survivorship of this behavioral bias in the highly dynamic and complex environment by computer simulation. Agent-based modeling may lead us to some viewpoints by pushing beyond the restrictions of the analytical approach."

A more detailed description of individual investor behavior might also be relevant for increasingly popular algorithmic trading, in which computational agents assist or act on behalf of human investors. It can be expected that these algorithms will become more sophisticated, by taking into account actual investment behavior and the insights from behavioral finance studies. In that sense, we also hope to inspire the modeling community for incorporating findings from behavioral finance research into their agent-based models. This may shed new light on the practical importance of such research, but it can also prompt behavioral finance researchers to provide more concrete inputs for modeling.

The paper is organized as follows: Section 2 provides a brief background of the behavioral finance research that focuses on individual investor behavior. In Section 3 we identify seven important topics of investment decision making and proceed with a literature review for each of the topics. Section 4 presents our conceptual model which consists of a cognitive model of the investor and the investment environment. The conclusion summarizes the main idea of the paper, and discusses the position of the agent-based approach relative to other research methods. The appendix provides definitions and examples for some of the most important heuristics and biases.

\footnotetext{
${ }^{1}$ Takahashi and Terano (2003) and Hoffmann et al. (2007) are rare examples of agent-based papers that pursue this idea of explicit accounting for behavioral theories in financial market simulations.
} 


\section{Background}

A research into individual investors and their behavior has received a lot of consideration during the past, and is increasingly in the focus of interest of many scientists, being not confined only to economists. However, the particular way of looking at individual investor has been subjected to a great paradigmatic shift with the inclusion of psychology, both its findings and its methodology, into financial studies ${ }^{2}$. Despite many ongoing debates, this has slowly led to the establishment of behavioral economics and behavioral finance as widely recognized subdisciplines.

"Behavioral finance, as a part of behavioral economics, is that branch of finance that, with the help of theories from other behavioral sciences, particularly psychology and sociology, tries to discover and explain phenomena inconsistent with the paradigm of the expected utility of wealth and narrowly defined rational behavior. Behavioral economics is mostly experimental, using research methods that are rarely applied in the traditional, mainstream finance literature." (Frankfurter and McGoun, 2000)

In social sciences, particularly economics, the term "Homo Economicus" has been used for a formal representation of an individual, who acts as a utility maximizer, given his preferences and other constraints. An economic man adheres to the axioms of rational choice theory. Even though this hypothetical construct has been useful in formulating economic theories and models, over the past decades psychologists and behavioral scientists have documented robust and systematic violations of principles of Expected utility theory, Bayesian learning, and Rational expectations - questioning their validity as a descriptive theory of decision making (DeBondt, 1998). Furthermore, Simon (1991), to whom the term "bounded rationality" is usually attributed, has emphasized "the limits upon the ability of human beings to adapt optimally, or even satisfactorily, to complex environments."

The efficient markets hypothesis (EMH), developed in the 1960's independently by Paul Samuelson and Eugene F. Fama, posits that market prices fully reflect all available information. The EMH is much intertwined with the Random Walk Hypothesis (RWH) according to which securities prices are unpredictable. "It has been applied extensively to theoretical models and empirical studies of financial securities prices, generating considerable controversy as well as fundamental insights into the price-discovery process" (Lo, 2007). Meir Statman, a notable

\footnotetext{
${ }^{2}$ Statman (1999), however, gives another perspective: "Some people think that behavioral finance introduced psychology into finance, but psychology was never out of finance. Although models of behavior differ, all behavior is based on psychology."

Yet another view is that economists distanced themselves from the psychological foundations of individual behavior during the development of neo-classical economics.
} 
proponent of behavioral finance, pleaded for "accepting market efficiency in the sense of beating the markets," however, rejecting the definition in the sense of rationality, by which "rational prices reflect only utilitarian characteristics, such as risk, not value-expressive characteristics, such as sentiment" (Statman, 1999). Burton G. Malkiel, one of the proponents of the EMH, embraces the definition of market efficiency "that such markets do not allow investors to earn above-average returns without accepting above-average risks" (Malkiel, 2003). Also, "What I do not argue is that the market pricing is always perfect. After the fact, we know that markets have made egregious mistakes, as I think occurred during the recent Internet 'bubble.' Nor do I deny that psychological factors influence securities prices..." (Malkiel, 2003). So, even though final opinions on EMH differ among academics, there appears to be at least some confluence of thought.

In order to reconcile the theory of efficient markets with behavioral finance, Lo (2005) proposes an alternative theory in which both can coexist - The Adaptive Markets Hypothesis. In this evolutionary model individual market participants adapt to changing environment by using heuristics. In other words, Lo provides us with a theoretical framework in which we could easily fit our conceptual model of the individual investor. Lo (2005) believes that if we were able to measure changes in investor population, changes in investor preferences, and changes in the investment environment, it might be possible to build actively managed portfolios that better suit an investor's needs.

One of the most influential contributions to the theory of decision making under uncertainty and risk, was made by Kahneman and Tversky (1979) with their Prospect theory. The robustness and pervasiveness of this cognitive-psychological research have bolstered its impact on the economic theory, as well as the finance (whose Modern portfolio theory is also based on the assumption of rational agents). Individual investors - who use heuristics, depend on framing of the problem, and are prone to biases, which in turn may lead to various anomalies at the market level - are subjects of research in the area of behavioral finance. "An empirical result qualifies as an anomaly if it is difficult to "rationalize" or if implausible assumptions are necessary to explain it within the paradigm," as said by Thaler (1987) throughout his series of papers on anomalies.

Behavioral finance builds itself upon two blocks: limits to arbitrage and psychology (Barberis and Thaler, 2003). Psychology lists a number of possible deviations from rationality, while limits to arbitrage argue that rational investors may not be able to exploit opportunities created by irrational investors. If irrational investors (noise traders) create dislocations in asset prices 
(departures from fundamental values), rational investors (arbitrageurs) should be able to correct this mispricing through the process of arbitrage. However, the arbitrage can be too costly, too risky, or simply impossible due to various constraints, so the inefficiencies may persist for a longer period (Barberis and Thaler, 2003). Behavioral finance finds its applications on various levels of financial markets: on the aggregate market level, on the cross-section of average returns, on individual investor behavior, and on corporate finance (Barberis and Thaler, 2003).

One of the earlier comprehensive studies of individual investors who manage their own equity portfolios, DeBondt (1998) identified four classes of anomalies on the level of individual investor behavior: Firstly, investors are prone to biases in the perception of asset price movements. In his 1987-1992 study, De Bondt conducted a mail survey among 125 investors affiliated with the American Association of Individual Investors (AAII), where he documented an extrapolation bias, that is, 'the expected continuation of past price changes.' Quite the opposite, in his 1991 study, by interpreting Livingston surveys data, he concluded that economic experts are contrarians in their predictions. Furthermore, investors predict too narrow confidence intervals in the subjective probability distributions of prices (Tversky and Kahneman, 1974). Secondly, the perception of asset's value is largely dependent on popular models (Shiller, 1990), that is socially shared tips from peers, financial advisors, news in the media (and nowadays, especially, on Internet portals, forums, and news groups). DeBondt and Thaler (1985) found evidence that stock market overreacts, i.e. violates Bayes' rule, as portfolios of prior losers outperform portfolios of prior winners. Thirdly, when managing risk and return, many investors do not diversify their portfolios. This may be due to false beliefs that the risk is defined at the level of an individual asset rather than the portfolio level, and that it can be avoided by hedging techniques, decision delay, or delegation of authority (DeBondt, 1998). Additionally, in their portfolios investors hold surprisingly large amounts of fixed-income securities (bonds), despite the empirical fact that stocks outperform them on the long run. Benartzi and Thaler (1995) have offered an explanation to this famous "equity premium puzzle" (Mehra and Prescott, 1985), by investors' myopic loss aversion - a combination of high sensitivity to losses, and frequent monitoring of one's wealth. ${ }^{3}$ Finally, although traders are often precommitted to certain rules and techniques, even professional ones seem to fail to maintain discipline and consistency (Slovic, 1972). Trading practices are highly influenced by two strong reference points - performance of the market index, and the price at which the asset was purchased.

\footnotetext{
${ }^{3}$ Haigh and List (2005) conducted an experimental analysis, and showed that not only undergraduate students exhibit myopic loss aversion, but also professional traders recruited from the Chicago Board of Trade (CBOT); the latter even to a greater extent.
} 
A number of surveys and books on behavioral finance and behavioral economics have been published, including some popular books aimed at individual investors (Shefrin, 2000; Goldberg and von Nitzsch, 2001; Barberis and Thaler, 2003; Camerer et al., 2004; Altman, 2006; Peterson, 2007). An excellent review paper about the emerging field of neuroeconomics is written by Camerer et al. (2005).

\section{Dimensions of Investment Decisions}

The real world setting implies dealing with an abundant complexity of financial markets, but modeling human behavior itself presents even greater challenge. To address this complexity, the question of investor decision making will be more narrowed focusing on relevant (but most likely interdependent) sub questions:

1. Profiling investors on their preferences and risk attitude;

2. Portfolio allocation in practice, diversification in practice, and the influence of various constraints;

3. Portfolio management, performance measurement, frequency of updating, employed strategies;

4. Information processing and learning;

5. Social interaction and peer influence;

6. The role of emotions and intuition;

7. Heuristics, biases, and departures from rationality;

\subsection{Risk}

The crucial concept for investments, and decision making in general, is the concept of risk. Unfortunately, there are many definitions of risk with its meaning varying across different domains. In standard decision theory, a risky prospect is expressed as a set of events and event-contingent outcomes, with probabilities assigned to each event. Knight (1921) made the distinction between decisions under risk and decisions under uncertainty, with risk being measurable (quantitative) and uncertainty non-measurable (non-quantitative). However, it is possible to conceive decision under risk as a special case of decision under uncertainty, where under risk objective probabilities are used, and under uncertainty subjective probabilities are used. The most influential theories for decisions under risk and uncertainty are known as Expected Utility Theory (Bernoulli 
(1954), von Neumann and Morgenstern (1944)), Prospect Theory (Kahneman and Tversky, 1979), Rank-Dependent Utility Theory (Quiggin (1982), Schmeidler (1989)), and Cumulative Prospect Theory (Tversky and Kahneman, 1992).

Traditional economics and finance have been dominated by these probabilistic models of uncertainty. However, other theories for dealing with uncertainty, ambiguity, or vagueness exist: e.g. fuzzy set theory (Zadeh, 1965), Dempster-Shafer theory (Shafer, 1976), and rough set theory (Pawlak, 1991).

Loomes (1999) suggests that the current evidence in literature is more in favor of the notion that individuals have only basic and fuzzy preferences, and that each decision problem triggers its own preference elicitation. This is in line with the claim that preferences are constructed (not elicited or revealed) as a response to a judgment or choice task (Bettman et al., 1998).

A decision maker's attitude towards risk can be characterized as risk-aversion, risk-seeking (risk-tolerance, risk-taking, risk-loving), or risk-neutrality; and can be defined in a classical sense as a preference between a risky prospect and its expected value (the method of revealed preference). In these theoretical considerations risk attitude is usually captured through the curvature of utility function, or alternatively, through nonlinear weighting of probabilities. But a strong empirical phenomena that is driving risk aversion to a large extent is known as loss aversion (Kahneman and Tversky (1979), Markowitz (1952)). "Losses loom larger than gains," and while people are typically risk-averse for gains, they are risk-seeking in the domain of losses (Kahneman and Tversky, 1979). This highlights reference dependence, i.e. the importance of reference point against which outcomes are coded as losses or gains.

Slovic (1998) argues that although knowledge of the dynamics of risk taking is still limited, there is an evidence of little correlation in risk-taking preferences across different domains and situations. Only those tasks highly similar in structure and payoffs have shown any generality. Also, previous learning experiences in specific risk-taking settings seem more important than general personality characteristics.

Furthermore, risk attitude can change depending on the outcomes of previous decisions. Thaler and Johnson (1990) found that previous gains increase risk-seeking behavior (house money effect), while in the presence of previous losses, those bets which offer a chance to break even seem particularly attractive (break-even effect). These are examples of what Thaler refers to as mental accounting. It is an important question whether investors have risk attitudes related to the gains and losses defined on the individual stock level (narrow framing), on parts of the portfolio, on the overall portfolio, or on their total wealth. 
Risk in investments is usually considered as the standard deviation of asset returns. Next to volatility, other common measures of risk are downside risk, shortfall probability, and Valueat-Risk. Finance and econometrics literature are the source of other more sophisticated risk modeling techniques.

In an early study of the judgmental processes of institutional investors, Cooley (1977) found that most investors perceive variance as a synonym or a large part of investment risk. A substantial number of investors, however, identified an additional dimension of risk in asymmetry (left skewness). Kurtosis, on the other hand, was perceived as risk-reducing. Investor perception of risk in security valuation can be biased. Shleifer (2000) illustrates this on an example of value and growth stocks, and conjectures that if this biased perception affects the demand for securities, while having nothing to do with the fundamental risk of a portfolio, it would still generate the same returns as we can observe in the data.

\subsection{Portfolio Allocation}

Modern Portfolio Theory (MPT) (Markowitz, 1959) lays the foundations of portfolio allocation from the normative point of view. Behavioral finance takes a descriptive perspective, by studying how individual investors actually allocate their portfolios.

In portfolio theory one of the crucial concepts is diversification, a risk-management technique where various investments are combined in order to reduce the risk of the portfolio. However, many investors do not (sufficiently) diversify their portfolios. This may be due to beliefs that the risk is defined at the level of an individual asset rather than the portfolio level, and that it can be avoided by hedging techniques, decision delay, or delegation of authority (DeBondt, 1998).

In choice theory diversification is a heuristic strategy of seeking for a variety of options. Simonson (1990) demonstrated a discrepancy in variety seeking between the sequential (separated) and simultaneous (combined) choices. Read and Loewenstein (1995) studied diversification bias in the context of consumer choices, and found that people choose more variety when making combined choices of quantities of goods for future consumption, than if they make separated choices immediately before the consumption. They attribute this bias to two mechanisms: (1) Time contraction, that is, a tendency to subjectively shrink (or neglect) the size of the interconsumption intervals when making simultaneous choices, thus overexaggerating the influence of satiation on preferences; (2) Choice bracketing, as an example of framing effects, that is, by the fact that simultaneous choices are presented as a bundle of options, they imply diversification as 
a natural heuristic, whereas sequential choices imply searching for the best preferred alternative in each choice.

Benartzi and Thaler (2001) studied naive diversification strategies in the context of defined contribution saving plans. They found an evidence of $1 / n$ heuristic, as a special case of diversification heuristic, in which an investor spreads his or her contributions evenly across available investment possibilities. They found a positive correlation between the relative number of equity options and the allocation to equities (equity exposure), which is consistent with the diversification heuristic. As the authors convey, such a strategy can be problematic both in terms of ex ante welfare costs, and ex post regret (in case the returns differ from historical norms). Naive diversification does not imply coherent decision making. Although it may be a reasonable strategy for some investors, it is unlikely that the same strategy would be suitable for all investors, who obviously differ on their risk preferences and other risk factors, such as age. $1 / \mathrm{n}$ heuristic can produce a portfolio that is close to some point on the efficient frontier, however the exact point might not match investors risk preferences - which can create a significant ex ante welfare costs (as exemplified by Brennan and Tourous (1999)). The strategy can also generate significant ex post regret in case the returns differ from historical norms (Benartzi and Thaler, 2001).

However, as shown by DeMiguel et al. (2007), naive diversification portfolio strategy is actually a very strong benchmark: by comparing out-of-sample performance of various optimizing mean-variance models, they found that no single model consistently beats the $1 / \mathrm{n}$ strategy in terms of Sharpe ratio or certainty-equivalent return. Poor performance of these optimal models is due to errors in estimating means and covariances. In order to beat the $1 / \mathrm{n}$ benchmark, much larger estimation windows should be used than what is actually used in practice (DeMiguel et al., 2007).

Huberman and DeMiguel (2006) studied 1/n heuristic in 401(k) plans by using a dataset of more than half a million participants. They found support for naive diversification, i.e. participants tend to allocate their contributions evenly across the funds that they chose, with the tendency weakening with the number of funds used. However, they also found that median number of funds used is three to four, which is insensitive to the total number of funds offered (four to fifty nine).

Furthermore, Benartzi and Thaler (2001) found a support for mental accounting on the company stock: when company stock is not in the array of available investment options, the contributions are divided evenly (nearly 50-50) between equities and fixed-income securities. However, when company stock is included, it captures around 40 percent of the assets, and 
the rest is divided about evenly between other equities and fixed-income securities. The total exposure to equities is 70 percent, as opposed to 50 percent when company stock is not available. It seams that company stock is given a separate mental account different from the rest of equity classes.

Home bias is another robust finding in portfolio allocation. Despite the advantages of international portfolio diversification, the actual portfolio allocation of many investors is too concentrated in their domestic market. French and Poterba (1991) estimate the domestic ownership share of the worlds five largest stock markets in 1990: 92.2 percent (US), 95.7 percent (Japan), 92 percent (UK), 79 percent (Germany), and 89.4 percent (France). So far, the literature has not provided a generally accepted explanation for the observed home bias.

Huberman and DeMiguel (2006) argue that "familiarity breeds investment," and that a person is more likely to invest in the company that she (think) she knows. Instances of this familiarity bias is investing in domestic market, in company stocks, in stocks that are visible in investors lives, and stocks that are discussed favorably in the media.

Goetzmann and Kumar (2001) examine the diversification of investors with respect to demographic variables of age, income, and employment. They found that low income and nonprofessional categories hold the least diversified portfolios. They also found that young active investors are overfocused and inclined towards concentrated, undiversified portfolios, which might be a manifestation of overconfidence.

\subsection{Portfolio Management}

Before discussing some of the main findings on how investors manage their portfolios, it is noteworthy mentioning that both EMH as well as much empirical evidence undermine practical relevance of active portfolio management. "Switching from security to security accomplishes nothing but to increase transactions costs and harm performance. Thus, even if markets are less than fully efficient, indexing is likely to produce higher rates of return than active portfolio management. Both individual and institutional investors will be well served to employ indexing for, at the very least, the core of their equity portfolio." (Malkiel, 2005)

While financial literature on active portfolio management offers various techniques for beating the benchmarks, behavioral literature focuses on how individual investors manage (or make changes to) their portfolios. A common tendency to hold losers too long and sell winners to soon, has been labeled by Shefrin and Statman (1985) as the disposition effect. They attributed

their findings to loss aversion, the issue of self-control, mental accounting, and the desire to 
avoid regret.

Odean (1998) found that a particular class of investors sell winners more readily than losers. Even when the alternative rational motivations are controlled for, these investors continue to prefer selling winners and holding losers. Their behavior is consistent with two behavioral hypothesis: the prospect theory, and a mistaken belief that winners and losers will mean revert. This investor behavior appears not to be motivated by a desire to rebalance portfolios or by a reluctance to incur the higher trading costs of low priced stocks. It is also not justified by subsequent performance, as, in fact, it leads to lower returns (Odean, 1998). Investors trade too much due to their overconfidence. For successful investors this overconfidence can be reinforced through self-attribution bias, i.e. belief that their trading success should be attributed mostly to their own abilities.

And while some investors may trade too much and often change their strategies, others may exhibit the tendency of "doing nothing or maintaining one's current or previous decision." This is how Samuelson and Zeckhauser (1988) defined the status quo bias. Explanations for the status quo bias fall into three main categories. The effect may be seen as the consequence of (1) rational decision making in the presence of transition costs and/or uncertainty; (2) cognitive misperceptions; and (3) psychological commitment stemming from misperceived sunk costs, regret avoidance, or a drive for consistency. The status quo is related to loss aversion (framing as gains and losses) in the sense that current position (status quo) is refereed as the reference point. Other explanations, such as anchoring, sunk costs, regret avoidance, the drive for consistency, the avoidance of cognitive dissonance, and the illusion of control, may contribute to the perseverance of the status quo bias. It is also related to the influence of default option on choices.

\subsection{Information processing}

Market participants are exposed to a constant flow of information, ranging from quantitative financial data to financial news in the media, and socially exchanged opinions and recommendations. Processing all this information is a daunting task, so it would not be surprising that during this process people apply many heuristics.

According to the representativeness heuristic people may overreact to a series of evidences, and see patterns where they do not exist. However, people can sometimes underreact to news, i.e. in the light of a new evidence they update their beliefs conservatively, and not in a fully Bayesian manner.

Processing information from the investment environment is important as it gives inputs for 
decision making, it updates beliefs, gives feedback on investment strategies, and fosters learning. However, the confirmation bias may play an important role in how investors acquire and process this information. It suggests that people have a tendency to search for information that supports their current beliefs and decisions, while neglecting information that confronts those beliefs.

Oberlechner and Hocking (2004) study information sources, news, and rumors in the foreign exchange market. In this study foreign exchange traders and financial journalists rated the importance of different information sources, such as wire services, personal contacts, analysts, daily newspapers, financial television etc. An interesting finding of this study is that the information speed, expected market impact, and anticipated market surprise are rated as more important than the reliability of the source, and the accuracy of information.

\subsection{Social interaction}

Financial economists have borrowed more from the psychology of the individual than from social psychology (Hirshleifer, 2001). Financial theorists have examined how information is transmitted by prices, volume, or corporate actions. However, person-to-person and media contagion of ideas and behavior also seems important.

Shiller (1990) has emphasized the importance of conversation in the contagion of popular ideas about financial markets. In a survey of individual investors, Shiller and Pound (1989) found that almost all of the investors who recently bought a particular stock had their attention drawn to it through direct interpersonal communication. The influence of conversation on trading may arise from individuals overconfidence about their ability to distinguish pertinent information from noise or propaganda (Hirshleifer, 2001).

Social psychology provides evidence of various social effects which might be important in the context of financial markets as well. Conformity effect, or the tendency of people to conform with the judgment and behavior of others, was studied by Asch (1956). Bond and Smith (1989) confirmed the conformity effect, showed its historical change, and emphasized its cultural dependence. Other important effects are fundamental attribution error and false consensus effect (see Hirshleifer, 2001).

Herding behavior or mimetic contagion has been proposed as the source of endogenous fluctuations (bubbles and crashes) in financial markets (Topol, 1991). This is interesting as it suggests that such market fluctuations may arise irrespectively of exceptional news or other exogenous shocks to the market. 


\subsection{Emotions}

Emotions have powerful effects on decisions, and decision outcomes have powerful effects on emotions (Mellers et al., 1998). Emotions can have both a predecision and postdecision effect. Most of the research focused on a unidimensional model in which a predecision emotion can be either positive or negative. However, a more detailed approach is needed given the variety and domain-specificity of emotions. Positive emotions are shown to increase creativity and information integration, promote variety seeking, but also cause overestimation of the likelihood of favorable events, and underestimation of the likelihood of negative events. Negative emotions promote narrowing of attention and failure to search for alternatives. They promote attributevs. alternative-based comparisons. One of the most studied emotions that can follow a decision is the feeling of regret. Gilovich and Medvec (1995) showed that in the short run people experience more regret for actions rather than inaction, while in the long run they experience more regret for their inactions. Anticipated emotions, such as regret and disappointment, have drawn most attention of economist, whereas immediate emotions (experienced at the moment of decision making) have been mainly studied by psychologists (Loewenstein, 2000). Loewenstein (2000) emphasizes that economists should also pay attention to immediate emotions and a range of visceral factors which influence our decisions.

One evidence for the importance of emotions in decision making comes from patients with brain lesions in regions related to emotional processing. Shiv et al. (2005) made an experiment with 20 rounds of investment decisions (choosing whether to invest 1 dollar in a risky prospect with a 50-50 chance of winning 2.5 dollars or nothing), and found that target patients (with brain lesions in emotion-related areas of brain) made more investments than the normal participants and control patients, and thus earned more on average. Normal and control patients seem to have been more affected by the outcomes of previous decision - upon winning or losing they adopted a conservative strategy and less invested in subsequent rounds. However, the inability to learn from emotional signals (Somatic Marker Hypothesis, Damasio et al. (1996)) can also lead to unadvantageous decisions such as excessive gambling. Thus, emotion and cognition both play a crucial role in decision making.

Loewenstein et al. (2001) propose "risk-as-feelings" perspective on decisions under risk and uncertainty, which differs from classical cognitive-consequentialist perspective in the sense that feelings or affects play a crucial role in decision making: emotional evaluations of risky choices may differ from cognitive, and when such a divergence occurs, they often drive behavior. Both emotional and cognitive evaluations are influenced by expected outcomes (and expected emo- 
tions) and subjective probabilities, however, emotional evaluations are also influenced by a variety of factors, such as vividness of associated imagery, proximity in time, etc.

Goldberg and von Nitzsch (2001) describe a personal experience of a trader (market participant) who goes through various emotional states during profit-and-loss cycles. The feelings of hope and fear, depending on the success or failure on the market, can be transformed to the states of euphoria or panic.

$$
\begin{aligned}
& \text { Hope } \rightarrow \text { pleasure } \rightarrow \text { elation }(\text { exuberance }) \rightarrow \text { euphoria } \\
& \text { Fear } \rightarrow \text { anxiety } \rightarrow \text { desperation } \rightarrow \text { panic/recklessness }
\end{aligned}
$$

During these transitional states there is a selective perception of information - positive information is perceived and often exaggerated, while negative information is ignored. In final states of euphoria or panic, information has almost no role to play (Goldberg and von Nitzsch, 2001). Even though individuals differ, the authors emphasize that everyone runs the risk of inability to make rational decisions under pressure.

\subsection{Heuristics and Biases}

This section presents different frameworks in which most known judgment heuristics and biases can be organized and presented. This frameworks were in most cases not intended to be unifying taxonomies of all possible heuristics and biases, but are merely the ways in which authors decided to present relevant heuristic and biases, and that we as such extracted from their literature. Organizing and presenting heuristics and biases is by no means an easy task, given that they arise from a wide range and cognitive mechanisms. However, a simple but comprehensive framework is important if one aims to use it for descriptive or prescriptive purposes.

A traditional approach describes decisions as choices between risky prospects. A decision maker forms beliefs about probabilities of events and about values (utilities) of outcomes contingent on those events. Finally, she makes preferences between risky options. Biases can arise both in the process of forming beliefs and preferences. In the more general sense, a bias can be defined as a departure from normative, optimal, or rational behavior.

Heuristics are rules of thumbs, procedures used for processing information and reasoning, often based on trial and error. They are useful as they make cognitively difficult tasks easier. However, they can also lead to systematic biases. When a biased behavior becomes systematic and robust, it gives a foundation for prediction of behavior. It is particularly important for 
financial markets where biased behavior can influence asset prices, and therefore affect behavior of more rational market participants too ${ }^{4}$.

In their seminal work, Tversky and Kahneman (1974) investigated heuristics that people often employ when making decisions under uncertainty. Heuristics are useful because they make the difficult task of assessing the probabilities related to uncertain events much easier. However, these heuristics can also lead to systematic biases in judgment. Three heuristics to which people are particularly susceptible are the following:

1. Representativeness.

2. Availability.

3. Adjustment and anchoring.

Hirshleifer (2001) proposed a unified explanation for most known judgment and decision making biases in the context of investor psychology and asset pricing.

1. Heuristic Simplification - the use of heuristic when making decisions.

(a) Attention/Memory/Ease-of-Processing Effects.

(b) Narrow Framing/Mental Accounting/Reference Effects.

(c) The Representativeness Heuristic.

(d) Belief Updating: Combining Effects.

2. Self-Deception

3. Emotions and Self-Control

(a) Distaste for Ambiguity.

(b) Mood, Feelings and Decisions.

(c) Time Preference and Self-Control.

4. Social Interactions

In his book "Greed and Fear" Shefrin (2000) identifies three important themes of behavioral finance:

1. A heuristic-driven bias

\footnotetext{
${ }^{4}$ The issue whether this could be exploited so as to create profitable opportunities is still rather controversial, and is related to a stance on the market efficiency. "I am skeptical that any of the 'predictable patterns' that have been documented in the literature were ever sufficiently robust so as to have created profitable investment opportunities, and after they have been discovered and publicized, they will certainly not allow investors to earn excess returns." (Malkiel, 2003)
} 
2. Frame dependence

3. Inefficient markets

The first two themes deal with individual decision making, while the last theme explains implications of individual behavior on the financial market. By heuristic-driven bias, Shefrin (2000) considers heuristics as rules of thumbs, usually generated through a trial and error process, which can also lead to systematic biases. Frame dependence deals with the distinction between the substance and the form, and means that the way in which a decision problem is presented also matters.

1. Heuristic-driven bias
(a) Representativeness bias
(b) Gambler's fallacy (the law of small numbers)
(c) Overconfidence (overly narrow confidence intervals)
(d) Anchoring and adjustment, conservatism
(e) Ambiguity aversion
(f) Emotion and cognition

2. Frame-dependence
(a) Loss aversion
(b) Mental accounting, frame dependence
(c) Hedonic editing
(d) Cognitive and emotional aspects
(e) Self control
(f) Regret
(g) Money illusion

Kahneman and Riepe (1998) focus on biases in beliefs and preferences of which financial advisors should be particularly aware, and provide recommendations how to avoid them or mitigate their harmful effects.

1. Judgment Biases (systematic errors of judgment)
(a) Overconfidence
(b) Optimism
(c) Hindsight 
(d) Over-reaction to Chance Events

2. Errors of Preference
(a) Non-Linear Weighting of Probabilities
(b) People Value Changes, not States
(c) Value Function
(d) The Shape and Attractiveness of Gambles

3. The purchase price as a reference point
(a) Narrow Framing
(b) Repeated Gambles and Risk Policies
(c) Short and Long Views

4. Living with the consequences of decisions
(a) Regrets of Omission and Commission
(b) Regret and Risk Taking

Real decision-making situations are characterized by complexity. They are influenced by many interdependent factors with inherent uncertainty. There is a continuous flow of information. Furthermore, decision problems are often not stable over time. To combat this complexity financial decision makers observe only essentials, and try to reduce the dimensionality of the problem (Goldberg and von Nitzsch, 2001). Goldberg and von Nitzsch (2001) define heuristics as mechanisms (rules, strategies) for processing information that arrive at a quick (not necessarily optimal) result following little effort. These authors divide heuristics into two major groups.

1. Heuristics for Reducing Complexity
(a) Simplifying the facts
(b) Mental accounting
(c) Availability
(d) Ignoring Information
i. Selective perception
ii. Contrast effects
iii. Primacy and priming effects

2. Quick Judgments
(a) Anchoring 
(b) Representativity

i. Overestimating probability

ii. Conjunction fallacy

iii. Gambler's fallacy

iv. Conditional probability fallacy

v. Overestimating empirical relationships

vi. Overestimating causal relationships

Barberis and Thaler (2003) survey behavioral finance literature with focus on the aggregate market level, on the cross-section of average returns, on individual investor behavior, and on corporate finance. Individual perspective is an application of psychology to financial markets. Barberis and Thaler (2003) list known biases that arise when people form their beliefs and preferences.

1. Beliefs
(a) Overconfidence
(b) Optimism and wishful thinking
(c) Representativeness
(d) Conservatism
(e) Belief Perseverance
(f) Anchoring
(g) Availability bias

2. Preferences
(a) Prospect Theory (other non-EU)
(b) Ambiguity aversion

Rabin (1998) discusses the following behavioral aspects.

\section{Preferences}

(a) Reference Levels, Adaptation and Losses
i. Loss aversion
ii. Endowment effect
iii. Status quo bias
iv. Diminishing sensitivity 
(b) Social Preferences and Fair Allocations

i. Equity, fairness, status-seeking

ii. Altruism

(c) Reciprocity and Attribution

i. Reciprocal altruism

ii. Volition

2. Biases in Judgment

(a) The law of small numbers

(b) Belief Perseverance and Confirmation Bias

(c) Hypothesis-based filtering

(d) Illusory correlation

3. Other biases

(a) Hindsight bias

(b) Availability bias

(c) Overconfidence

Shefrin (2000) takes the so-called debiasing view, by which costly mistakes can be avoided if practitioners learn how to recognize mistakes, understand the underlying reasons, and finally avoid them. Kahneman and Riepe (1998) find the ability to recognize situations in which one is likely to make a large error a useful skill for a decision maker. Critical or analytical thinking must be employed, whenever intuition cannot be trusted. Goldberg and von Nitzsch (2001) believe that individuals could increase their trading success by "knowing thyself," by being aware of these mechanisms, and by a little discipline.

Many proponents of behavioral finance seem to share this view. However, some questions immediately arise, as it is not completely clear what the prerequisites for a successful implementation of this debiasing are. How do investors realize they are biased - is it through market feedback, their own introspection, or social interaction? How do they implement debiasing, and how do they evaluate this process? "Why dont people simply learn their way out of biased judgments? To some extent they do. One barrier is that learning is just too hard. The other barrier arises from self-deception." (Hirshleifer, 2001)

Some biases may be avoided by careful framing of problems or by learning effects of repetition. However, there is no guaranty that financial decision problems will be presented in such a 
way which promotes an unbiased decision making process, as noted by Hirshleifer (2001). Inexperienced market participants should be particularly careful, as they have not been exposed to these positive learning effects. Similarly, Kahneman and Riepe (1998) identify three necessary conditions for a good calibration (i.e. avoiding overconfidence):

1. Facing the same problem every day;

2. Making explicit probabilistic predictions;

3. Obtaining swift and precise feedback on outcomes;

Standard economists, however, may argue that individual biases are not that important, as individuals differ, so their biases should cancel out in the equilibrium. However, it is well-known that some biases can be systematic and persistent (Hirshleifer (2001)). Repeated patterns can even be used as a basis for prediction of behavior of others, which is very important in the context of financial markets (Goldberg and von Nitzsch (2001)).

Behavioral finance literature gets into the very heart of the debate about rationality and irrationality of market participants. Thaler (1991) makes an interesting remark about that: "If most individuals tend to err in the same direction, then a theory which assumes that they are rational also makes mistakes in predicting their behavior." A typical example in a gametheoretical setting is a game (reminiscent of beauty contest games) in which every participant must write down a number between 0 and 100. The winner of the game is the participant whose number is the closest to two thirds of the average value of all the numbers given by participants. Even though the rational solution to the problem is 0 , experiments show that winning numbers are usually larger. A proposed explanation for this out-of-the-equilibrium behavior involves subjects engaging in a finite-depth of reasoning about other subjects' beliefs (Nagel, 1995). A player who wants to win the game should deliberately depart from the Nash equilibrium solution, by taking into account that not all players are fully rational (Thaler, 2000). Financial markets might be a real-world example where rational behavior does not necessarily imply success. And while in the previously mentioned game (when repeated) learning would lead players to the equilibrium, in the real market there may be not be such learning opportunities, and/or there might be an inflow of new irrational investors.

Finally, heuristics and biases should not be treated as synonymous. Heuristics do not always lead to biases, and even if they do (with respect to some normative rational theory), heuristic behavior may actually result in a successful performance compared to an optimal strategy, which was demonstrated in the famous paper by Gigerenzer and Goldstein (1996). Another example is the previously mentioned naive diversification, i.e. $1 / \mathrm{n}$ heuristic. 


\section{Conceptual Model}

\section{$4.1 \quad$ Introduction}

The conceptual model of the individual investor behavior presented in this paper is built for the purpose of further implementation into agent-based artificial financial market. Of course, individual behavior could be directly implemented into such a computational model. However, building a separate conceptual model has a number of advantages. A conceptual model is a structured representation of the large diversity, complexity, and interdisciplinarity presented in the field. By building a conceptual model we can become aware of the interrelations between components we may not otherwise see, we can indicate the strength of these relationships, and we can identify those areas which are still largely unknown, thus fostering future research. From a modeler's perspective, a conceptual model gives a structure that is easier to implement. On top of the same conceptual model various implementations can be made, for instance, using mathematical, or computational modeling techniques.

In this conceptual model investment decisions are seen as an iterative process of interactions between the investor, as represented by the cognitive model (Figure 1) and the investment environment (Figure 2). This investment process is influenced by a number of interdependent variables and driven by dual mental processes. The interplay between these systems contributes to boundedly rational behavior in which investors use various heuristics and can exhibit biases. In the modeling tradition of cognitive science, the investor is seen as a learning, adapting, and evolving entity that perceives the environment, processes information, acts upon it (make changes to portfolio), and updates its internal states. Finally, the investor behavior is influenced by social interactions with his or her peers. This model can be used to build stylized representations of (classes of) individual investors, and further studied using the paradigm of agent-based artificial financial markets.

\subsection{Cognitive Model of the Investor}

\subsubsection{Dual-process Systems}

Our cognitive model of the investor (Figure 1) is based on a two-dimensional framework of neural functioning, as proposed by Camerer et al. (2005), which distinguishes between affective and cognitive, and between controlled and automatic processes.

A distinction between controlled and automatic processes can be found in psychology literature under various names of dual-processing theories (see Camerer et al., 2005)). Controlled 
processes are serial (step-by-step), evoked deliberately, they cause the subjective feeling of effort, and are accessible by introspection. Automatic processes operate in parallel, they are relatively effortless, and are inaccessible to consciousness.

A distinction between affect and cognition is also pervasive in contemporary psychology and neuroscience literature (Camerer et al., 2005). Affective processing is associated with feeling states when affect states reach a certain threshold level. However, most of the affective processing operates unconsciously. The central role of affective processing is in human motivation affects address "go-no go" questions, while cognitive processes address "true or false" questions (Camerer et al., 2005).

In dual-process theories the choice is determined as the result of the interplay between the cognitive and affective system. This interaction can be collaborative (when both systems work in the same direction), or competing (in which one system wins and overrides the other system). A number of variables can influence the relative strength of these systems, e.g. cognitive load can easily undermine controlled cognitive processes.

Much of the findings in behavioral economics and finance can be interpreted in the light of the dual-process theories. So, for a modeler, it might be just an appropriate level of abstraction, without the need to go into more complex details of cognitive mechanisms and neural functioning.

\subsubsection{Risk Attitude}

The conceptual model also captures important variables in financial decision making, such as risk attitude and time preference. Risk attitude (risk aversion, risk neutrality, risk seeking) is influenced by the competition and collaboration between the cognitive and affective system (Loewenstein et al., 2001) Cognitive system is assumed to deal with risk in a probabilistic fashion, similar to traditional choice theories. Risk averse behavior is driven by fear and anxiety responses to risk and the stored pain of experienced losses (Camerer et al., 2005). Risk taking behavior is driven by the pleasure of gambling (Camerer et al., 2005). The feelings need not be mediated by the cognition. In the light of the Prospect Theory, Loewenstein and O'Donoghue (2004) propose that the affective system contributes to the risk attitude through loss aversion and non-linear (usually S-shaped) probability weighting; however the deliberative system responds to risk in a way predicted by Expected Utility Theory (or perhaps Expected Value). To support this interpretation, the authors point to research which suggests that emotional responses depend on mental images of outcomes, whereas they tend to be insensitive to probabilities.

Risk component of the model is related to risk factors such as gender and age. A meta- 
analysis study by Byrnes et al. (1999) confirmed a significantly higher propensity for risk taking in male participants. In addition, they found age-related shifts in this gender gap, particularly the tendency of the gender gap to decrease with age. Donkers et al. (2001) show that an individual's risk attitude and probability weighting function is influenced by gender, education level, age and income.

Besides demographic factors, such as gender and age, an important variable influencing risk attitude is the investment horizon. "Most investment practitioners subscribe to the time diversification principle, which states that portfolio risk declines as the investment horizon lengthens. Accordingly, practitioners commonly advise younger clients to allocate a larger proportion of their retirement money to risky assets than older clients do. In contrast, many respected theorists argue that time diversification is a fallacy." (Jaggia and Thosar, 2000). In their opinion, the answer lies in the psychology of risk-taking, particularly as it relates to time horizon. In favor of the time diversification position, they "argue that risk perception is not only a function of age (and other cross-sectional idiosyncratic factors) but also of the temporal distance between the initial investment point and the cash-out point typically represented by the individuals retirement." (Jaggia and Thosar, 2000)

Gilovich et al. (1993) have studied the effect of temporal perspective on subjective confidence, and they found that people tend to lose confidence in their prospects for success as they come closer to the moment of truth, i.e. "the risk-assessment becomes more conservative with shorter temporal distance."

\subsubsection{Time Preference}

Time preference is in standard economic theory captured with the discount factor of the discounted utility (DU) model (Samuelson, 1937). However, a behavioral point of view suggests that modeling time preference with a constant discount rate may not be suitable for descriptive purposes. Hyperbolic discounting has been proposed to capture an empirical observation that between now and a point in the future people discount more than between two other temporally equidistant points in the far future, i.e. the discount rate is declining over time (Laibson, 1997).

An opposing finding by Read (2001) suggests that an observed pattern of time preference could be also explained by subadditive discounting, or a finding that the amount of "discounting over a delay is greater when the delay is divided into subintervals than when it is left undivided." (Read, 2001)

Frederick et al. (2002) review time discounting literature, and list the anomalies which con- 
tradict the DU model, namely: (1)the sign effect; (2) the magnitude effect; (3) the delay effect; (4) preference for improving sequences; and (5) violations of independence and preference for spread. They conclude: "we believe that economists' understanding of intertemporal choices will progress most rapidly by continuing to import insights from psychology, by relinquishing the assumption that the key to understanding intertemporal choices is finding the right discount rate (or even the right discount function), and by readopting the view that intertemporal choices reflect many distinct considerations and often involve the interplay of several competing motives."

Time domain enters the conceptual model when choosing the investment horizon, the frequency of update, as well as in planning, forecasting, and discounting. An interplay between cognitive and affective mechanisms might give even more refinement in modeling time preference. Affective system is inherently myopic and impulsive, motivating behaviors that have short-term goals, whereas higher order cognitive functions of the prefrontal cortex can take long-term consequences and planning into account (Camerer et al., 2005; Shefrin and Thaler, 1988). According to Camerer et al. (2005) factors which strengthen or weaken an affective or cognitive system will influence people to behave more or less impulsively. Any factor which imposes cognitive load on the prefrontal cortex, i.e. the controlled cognitive system, will decrease the influence of this system on behavior. Other factors which can diminish the power of self-control are a previous exercise of self-control, alcohol, stress, and sleep deprivation. Analogously, "the activation of affective states should accentuate temporal myopia." (Camerer et al., 2005).

\subsubsection{Personality}

Psychological literature on personality has settled around a five-factor model (Digman, 1990):

1. Extraversion

2. Agreeableness

3. Conscientiousness

4. Neuroticism

5. Openness

Recent studies have examined a possible influence of personality traits on financial decisions, particularly in the context of daily traders. Fenton-O'Creevy et al. (2004) conducted a study among 118 professional traders employed at investment banking institutions, and showed that successful traders tend to be emotionally stable introverts open to new experiences. Contrary to these results, Lo et al. (2005) found the lack of correlation between personality traits and 
trading performance. "This raises the possibility that different personality types may be able to function equally well as traders after proper instruction and practice. Alternatively, it may be the case that individual differences pertinent to trading success lies below the level that can be assessed through personality questionnaires, and may become visible only at deeper physiological and neuropsychological levels, or with a larger or more homogeneous sample of traders." Lo et al. (2005)

Given the current inconclusive results, the link between personality traits and investment performance might still be far-fetched. However, the relationship between personality and risk attitude, time preference, investment strategies, or susceptibility to particular behavioral biases might be relevant for practical investment purposes - especially given the availability of various batteries for testing personality types, and given the stability of personality traits during a long period of a lifetime.

The link between personality traits and risk propensity has been fairly studied in the literature: McCrae and Costa (1996) found sensation-seeking, a sub scale of the Extraversion dimension, to be highly correlated with most risk-taking domains, while overall risk propensity was higher for subjects with higher Extraversion and Openness scores and lower for subjects with higher Neuroticism, Agreeableness, and Conscientiousness scores (Lo et al., 2005). Zuckerman and Kuhlman (2000) studied the relationship between personality types and risk-taking behavior in various domains: smoking, drinking, drugs, sex, driving, and gambling. They found impulsive sensation seeking, sociability, and aggression to be related to risk-taking behavior, whereas neuroticism/anxiety and activity were not related.

The influence of personality traits has been studied in various game-theoretical experiments, as summarized by Lo et al. (2005): "For example, higher extraversion and emotional stability - the opposite of neuroticism - appear to be related to a higher level of stability in intertemporal consumption patterns (Brandstätter and Güth, 2000). In Dictator and Ultimatum games, higher benevolence as a personality trait facilitated more equitable choices in offers to powerless opponents, and reciprocity orientation induces powerful recipients to set higher acceptance thresholds (Brandstätter and Güth, 2002). Greater internal locus of control, better self-monitoring ability, and higher sensation-seeking have all been linked to higher levels of cooperative behavior in Prisoner's Dilemma experiments (Boone et al., 2002)" 


\subsubsection{Goals}

Investor behavior, like most human behaviors, can be conceptualized as goal-oriented, which means that investors make decisions in order to reach their various financial and non-financial goals. Goals are in the broad sense defined as mental (internal) representations of desired states (Austin and Vancouver, 1996), and here we study preferences, objectives, and constraints.

Custers and Aarts (2005) summarize modern theories of motivation and goal-directed behavior: "the probability that a given goal state is set, adopted, and enacted depends on people's ability (a) to mentally access the representation of the goal; (b) to subjectively assess the expected (or incentive) value of the goal state; (c) to activate, select, and execute instrumental actions; (d) to detect, assess, and reduce the discrepancy between the actual and desired state." In this framework, positive affect linked to a goal representation is capable of directly feeding the motivation system, thus, propelling the goal pursuit behavior (aimed at attaining the desired state) (Custers and Aarts, 2005).

While economic agents are classically assumed to be self-interested, the list of motivators could be enriched by taking into account also social preferences, such as fairness, altruism, revenge, status seeking and survival.

\subsubsection{Strategies}

There is an abundant pool of strategies that investors use for the valuation of assets, for stock picking, and market timing. To obtain an overview of the basic groups of strategies, we look at some standard investment books.

Sharpe et al. (1999) present investment decision-making as an iterative process comprised of several steps.

1. Investment Policy - determining investor's objectives in terms of risk-return tradeoff, the amount of investable wealth, tax status, etc.

- Mission statement - long term financial goals (e.g. saving for child's education);

- Risk tolerance - the amount of risk an investor is willing to bear when pursuing financial goals;

- Investment objectives - specific investment results that indicate success (e.g. market index as a benchmark);

- Policy asset mix - allocation to broad asset classes;

- Active management - the extent to which the investors tries to beat the benchmarks; 
2. Security Analysis - analysis of individual securities within previously identified broad classes;

- Technical analysis - forecasting future price movements on the basis of historical data;

- Fundamental analysis - estimating the intrinsic price as the present value of future cash flows;

3. Portfolio Construction - determining in which assets to invest, and what proportion of wealth;

- Selectivity (microforecasting) - security analysis of individual security prices;

- Timing (macroforecasting) - movements of common stocks relative to fixed-income securities;

- Diversification - constructing the portfolio to minimize risk subject to certain constraints;

4. Portfolio Revision - periodic repetition of previous steps, as over time investors objectives and prices of securities change;

5. Portfolio Performance Evaluation - measuring the return and risk of portfolio, as well as benchmarking.

Similarly, Levy and Post (2005) describe the investment process as:

1. Investment Policy - determining investor's objectives and constraints (liquidity needs, time horizon, tax considerations, legal and regulatory, unique needs, circumstances and preferences);

2. Investment Vehicles - exploring available investment opportunities across broad asset categories in terms of risk-return tradeoff;

3. Strategy Development - optimization with respect to investment vehicles and investor characteristics;

4. Asset Allocation - proportioning of an investment portfolio among various asset categories;

5. Security Selection - decision-making process to determine securities within each asset class that are most suitable for investor needs;

6. Strategy Implementation - taking into account transaction costs and liquidity;

7. Strategy Monitoring.

Sharpe et al. (1999) describe investment styles that consist of different processes: 
- Security Selection;

- Security Selection and Asset Allocation;

- Security Selection, Sector Selection, and Asset Allocation;

- Market Timing

The normative/prescriptive approach of standard investment books is essentially a top-down approach in which an important step is asset allocation, i.e. investment decision on the level of broad asset classes. Asset allocation can be strategic (based on long-term forecasts) or tactical (based on short-term forecasts). However, a fully bottom-up approach occurs in practice too it focuses on specific assets that offer most attractive investment opportunities, without much concern for the resulting asset allocation, and as such may lead to a portfolio that is industryor country-specific, or exposed to one source of uncertainty (Bodie et al., 2006). A descriptive model must be able to describe the behavior of investors who follow any of the two approaches to asset allocation, as well as various investment styles.

\subsubsection{Perception - Interaction - Action}

Perception, interaction and action are processes which describe the way in which investor interacts with the investment environment in which he or she is situated. Processes such as perception and action are commonly included in cognitive models (e.g. Sloman (2001)).

Perception is the process of acquiring information incoming from various sources in the investment environment (classical media, such as television, radio, and paper news, as well as various Web applications). Through communication channels, other market participants (peers) can also serve as sources of information. Information can be quantitative or qualitative, and can include financial data, news, tips, etc.

Information processing of the acquired information could also be interpreted in the light of the dual-process systems. For instance, information could be used for controlled deliberative reasoning (e.g. whether it fits expectations), but also by an affective system (e.g. emotional response to price changes). Cognitive system is expected to deal with information processing by applying simplifying heuristics, while emotional system can be susceptible to hedonic editing and confirmation bias. These inputs from the environment are necessary to establish a feedback mechanism as the basis for learning. A dual-process view taken in this paper suggests that learning processes are likely "a splice of cognitive and affective processes" (Camerer et al., 2005). Since literature on individual and social learning is vast, we also suggest a review paper by 
(Brenner, 2006), which presents different types of learning that could be implemented within intelligent economic agents.

Interaction is that part of the model which deals with peer influence and social factors, and can be introduced into the model as the formation of information cascades and herding type of behavior.

Action is performed when an investor wants to change his or her current portfolio. It can be characterized by the security that investors wants to buy or sell, a type of order, the size of the order, the timing, and other parameters characteristic to a particular type of order (e.g. price contingencies). The most common types of orders are market order and limit order. More about various types of orders and their properties can be found in (Harris, 2003). Our conceptual model can account for various underlying causes for a particular action, such as a trading strategy, peer influence, a habit, or an emotional response to financial news or price changes.

\subsection{Investment Environment}

The investment environment in which investors operate is shown on Figure 2, and is based on the description of trading industry by Harris (2003). Harris defines traders as people who trade, and who may either arrange trades for themselves, have other people arrange trades for them, or arrange trades for others. Accordingly, he distinguishes between:

1. proprietary traders - trade for their own account;

2. brokerage traders (agency traders, commission traders, commission merchants) - arrange trades as agents for their clients.

This distinction is particularly important as it can be expected that traders who trade with other people's money have different incentives and goals than those who trade for their own account.

Furthermore, trading industry can be grouped into two sides of traders (Harris, 2003):

1. Buy Side - traders who buy exchange services (such as liquidity, or the ability to trade when you want); Buy side includes individuals, funds, firms and governments. Institutions on the buy side (such as pension funds, mutual funds, trusts, endowments, foundations) are known as investment sponsors. Investment sponsors have investment advisers (investment counselors, investment managers, or portfolio managers), and employ traders who implement their decision. Beneficiaries are people/institutions that will ultimately benefit from the funds held by investment sponsors. 
2. Sell Side - traders who sell exchange services (such as liquidity) to the buy side. Sell side consists of:

- Dealers - accommodate trades that (and when) their clients want to have. They profit by buying low and selling high;

- Brokers - trade on behalf of their clients. They arrange trades for their clients by finding other traders who will trade with them. They profit from commissions paid by their clients.

- Broker-dealers - dual traders that both deal and broker trades.

According to Harris, investors are seen as traders who trade in order to move their wealth from the present to the future. Borrowers, hedgers, asset exchangers, and gamblers have other incentives for trading. What is interesting here is that trader is a generic term that encompasses all market participants. Conversely, a trader, such as a day-trader, could be seen as a special type of investor who has a very short investment horizon. In such a context investors are usually market participants who have a longer investment horizon and employ some sort of portfolio management. Agent-based literature does not always precisely define what is meant by investors or traders, so terms such as investors, traders, and agents are sometimes used interchangeably. What we have in mind in this paper and in Figure 1 is a broader definition of investors (including different types of traders), as we believe that this conceptual model of investor could be used to represent various classes of market participants by an appropriate instantiation of the elements of the model, particularly goals and strategies.

Trade facilitators are institutions that help traders trade (Harris, 2003):

- Exchanges - provide forums for traders (dealers, brokers, and buy-side traders) to meet and arrange trades. At most exchanges only members can trade, while nonmembers trade by asking member-brokers to trade for them. Traders used to meet at the trading floor, but now they meet via ECNs (electronic communication networks). At some exchanges traders arrange trades when they see fit, while other exchanges have order-driven systems that arrange trades by matching buy and sell orders according to a set of rules. OTC (over the counter) is trading that occurs outside exchanges, arranged by dealers and brokers.

- Clearing Agents - they match buyer and seller records and confirm that they both agree to the same terms.

- Settling Agents - they help traders settling their trades by giving the cash to the seller and the securities to the buyer. 
- Depositories and Custodians - they hold cash and securities on behalf of their clients, and help them in settling trades by quickly delivering cash and security certificates.

Modeling trade facilitators is a challenge itself, particularly if one wants to model real financial exchanges as realistic as possible. Most agent-based papers do not go into that level of detail, and instead use simple trading mechanisms or even price impact functions.

Harris (2003) organizes trading instruments into the following classes:

1. Real assets - physical commodities, such as real estates, machines, or patents and other intellectual properties;

2. Financial assets - instruments that represent ownership of real assets and the cash flows that they produce;

3. Derivative contracts - instruments that derive value from the value of underlying instruments upon which they are based;

4. Insurance contracts - instruments that derive value from future events related to losses;

5. Gambling contracts - instruments that derive value from future events related to gains;

6. Hybrid contracts - instruments that embody elements of more types of instruments.

These classes can further be divided into subclasses. For instance, financial assets can be divided into domestic and international, based on size (big, mid, small caps), based on style (value, blend, growth), etc. These asset classes have an important role in the process of asset allocation. However, most of the (behavioral) finance literature focuses on financial assets, particularly on equities. It is not surprising then that most agent-based artificial financial markets are actually artificial stock markets. Furthermore, many agent-based papers focus only on one risky asset, while a more realistic approach should deal with multi-asset environments and the intricacies of correlations among them.

\section{Conclusion}

This paper presented a descriptive model of individual investor behavior in which investment decisions are seen as an iterative process of interactions between the investor and the investment environment. This investment process is driven by dual mental processes (cognitive and affective), and the interplay between these systems contributes to boundedly rational behavior which manifests itself through various heuristics and biases. In the modeling tradition of cognitive science and artificial intelligence, the investor is seen as a learning, adapting, and evolving entity 
that perceives the environment, processes information, acts, and updates its internal states. Finally, the investor behavior is influenced by social interactions.

The aim of this model is descriptive, that is, to be able to capture and describe observed behavioral phenomena. However, these behavioral phenomena stem from a wide variety of cognitive mechanisms and other sources, which makes it difficult to integrate them into a simple and parsimonious framework. Furthermore, in case a normative model exists, a descriptive model is expected to be more general (in order to capture the behavior of those who depart from the norm, and those who act accordingly). The resulting model is an eclectic model with many interdependent variables, i.e. every variable is influenced by the current states of other variables, by cognitive and affective processes, and by the feedback mechanism. It is rather ambitious task to determine the nature of all these relationships. However, it is possible to indicate some of the relationship by finding evidence in the existing behavioral finance literature.

A common critique of behavioral finance research is that it only criticizes the mainstream finance, but does not offer alternative models nor generate fresh predictions. For the latter, we suggest modeling using new computational techniques, namely the agent-based approach. Agent-based models can easily accommodate complex learning behavior, asymmetric information, heterogeneous preferences, and ad hoc heuristics (Chan et al, 1999). Such models could be used for assessing the relevance of behavioral research findings, for studying scenarios for which empirical data is unavailable, and as hypotheses generating tools.

To address the issue of validity of the agent-based research, let us start with some alternative methodologies that can be used for studying the research questions in behavioral finance. Traditionally, behavioral finance had used mostly experiments, and there have been many studies in which subjects participated in various investment tasks. Furthermore, most of the behavioral biases and heuristics originate from experiments conducted by cognitive psychologists. One of the common critiques of these experimental studies is that they are often conducted only with student participants, rather than actual traders and investors. This critique is not always valid, since robust findings obtained with student participants can often be generalized to a broader population. One example are experiments with myopic loss aversion, in which professional traders exhibited this bias even to a greater extent than students. Another disadvantage of experiments is that participants face such financial outcomes (almost exclusively gains), which cannot be compared to gains and losses that investors face in real financial markets. It is considered that shifting from laboratory to field experiments, where possible, would increase external and ecological validity. 
A different methodology used in (behavioral) finance is the quantitative analysis of actual trading records. These databases are very difficult to obtain, but to a researcher who has acquired such a database they provide a compelling argument of working with actual trades made by investors. However, even though the performance of individual investors can be determined from the data, the explanatory variables used in such studies often do not go beyond simple demographics, such as age, gender, and education. But we would like a richer description of investors, possibly about their strategies, psychological profiles, propensity to behavioral biases etc. This could be explored by using questionnaires with market participants to proxy for hardly observable psychological traits. Unfortunately, such information is difficult to obtain from real investors and traders, even decoupled from the database of their actual trades ${ }^{5}$.

Whereas experiments are good in capturing behavior in controlled environments, they might lack generalizability to real financial markets ${ }^{6}$. Would similar behavior occur in financial markets, how would if affect the performance of individual investors, and how would it aggregate to the market level? Quantitative analysis of financial data may answer some of these questions, but it is not always clear what is the exact behavior of market participants that lead to it. Agent-based artificial financial markets are potentially able to fully bridge this gap between individual investor behavior and aggregate market phenomena, by allowing the modeler to specify the behavior of market participants, to implement various market mechanisms, and to analyze the resulting asset prices. In such a way, artificial financial markets can be used as a tool to generate and/or test various behavioral hypothesis and theories.

However, artificial stock markets, as a very rich simulation tool, also raise questions of their validity. One source of (descriptive) validity can be found in a descriptive approach where agents

\footnotetext{
${ }^{5}$ Dorn and Huberman (2005) is an example of such a study, where survey responses are combined with trading records in order to give better understanding of why investors fail to buy and hold a well diversified portfolio. In this study stated perceptions and self-assessments are used to develop proxies for psychological traits such as risk attitude and overconfidence. Overconfidence has been proposed as the cause of overtrading and poor performance of investors (Odean, 1998). However, there exist many operational definitions of overconfidence, such as an overestimation of relative knowledge, and miscalibration (an overestimation of the precision of private information.) For modeling purposes miscalibration seems to be the most obvious choice. For example, Takahashi and Terano (2003), in an agent-based paper that deals with behavioral issues, model overconfidence as an underestimated variance. Glaser and Weber (2007) suggest that, even though widely used, miscalibration may not be the best proxy for overconfidence; in their study they could not relate measures of miscalibration to measures of trading volume.

${ }^{6}$ Given that most biases shown in these experiments come from hypothetical static risky choice problems, a great caution should be exercised when introducing such results into highly dynamic financial models (Chen and Liao, 2003).
} 
are modeled to show behavior found in actual traders and investors. This is difficult to achieve, but it is also not necessary, as one can take a positive approach in which assumptions on behavior need not be descriptively valid. Most studies of artificial financial markets analyze generated price or return series to check whether they exhibit fat tails of distributions, volatility clustering, and other stylized facts observed in real financial data. A model that can generate such stylized facts is considered to be more realistic. The most critical part of a model validation is explaining how these (realistic) inputs (investor characteristics, preferences, behavior) are mapped into (realistic) outputs of the model (price time series, market dynamics). Analytical models are more easily tractable, but they are constrained with respect to achieving realistic inputs and outputs. Computational models are more powerful in obtaining valid inputs and outputs, but are more difficult to understand, analyze, and explain ("black boxes"). Some researchers utilize their knowledge of nonlinear system dynamics, chaos theory, and econometrics to tackle this problem.

Conceptual model of individual investor behavior presented in this paper aims to summarize and structure part of the vast knowledge about investor behavior that is present in the (behavioral) finance field. It can serve as a pool of ideas for agent-based models of financial markets that aim at a more complex and a more realistic representation of investor behavior. 


\section{A Heuristics and biases}

This appendix list most known heuristics, biases, and effects, by focusing on:

1. definition (or definitions by different authors);

2. experimental examples;

3. financial examples or possible implications for investment decisions;

\section{A.1 Ambiguity Aversion}

"The emotional aspect of the aversion to ambiguity is the fear of unknown" (Shefrin, 2000).

\section{A.2 Anchoring and Adjustment}

Adjustment and anchoring is a heuristic which starts from an initial value (given by the problem formulation, or by some partial computation) and then adjusts it towards the final value. The problem with this heuristic is that the adjustment is often insufficient, which means that the final value will heavily depend on the initial value. The consequence of this heuristic is that people overestimate conjunction of events (with high individual probabilities), and underestimate a disjunction of events (with low individual probabilities). Anchoring effect is also present in the assessment of subjective probability distributions, resulting in overly narrow confidence intervals.

Overstrong anchoring to the status quo often results in underestimation of the probability of extreme movements (Lichtenstein et al, 1982). Setting confidence intervals overly narrow means that people get surprised more frequently than what they expect (Shefrin, 2000). In financial markets anchors can be based on opinions or attitudes of friends or experts. Even data and forecast that initially appear to be unrealistic can still have an anchoring effect (Goldberg and von Nitzsch, 2001)

\section{A.3 Availability}

Availability is a judgmental heuristics in which a frequency/probability of a class/event is assessed on how easy it is to recall its instances (retrievability), how easy it is to mentally construct its instances (imaginability), or how easy it is to associate two instances (illusionary correlation), Tversky and Kahneman (1974).

In (Tversky and Kahneman, 1973), the authors analyze availability, a heuristic which uses the strength of association between instances to asses their probabilities. For example, in one study subjects were asked to compare the frequencies of words starting with letter 'r', and 
words that have letter 'r' in the third position. Even though the latter are more frequent, the participants opted for the first case, because it is much easier to mentally construct words by using their first letter. Similar results can be obtained when testing different mental operations. For retrievability, the frequency of instances which are more easily brought to mind (retrieved) looms larger. Another availability heuristic assesses the frequency of co-occurrences by the ease of making association between objects.

\section{A.4 Conditional Probability Fallacy}

Conditional probability fallacy means confusing conditional probability $p(a \mid b)$ with $p(b \mid a)$, and can be in a broader view considered as the fallacy of confusing cause and effect. Goldberg and von Nitzsch (2001) gives a financial example where the probability of a stock market crash in October is overestimated based on the historical observation that most stock crashes occurred in October.

\section{A.5 Conservatism}

People respond too conservatively to new information. This is related to Anchoring and Adjustment heuristic. In a narrow sense conservatism means that people are not perfect Bayesian updaters.

\section{A.6 Endowment Effect}

Once a person comes to possess a good, the person immediately values it more (Thaler, 1980; Knetsch and Sinden, 1984).

\section{A.7 Frame Dependence}

A frame is the form used to describe a decision problem, and frame dependence means that the form is relevant for behavior (Shefrin, 2000).

\section{A.8 Gambler's Fallacy}

See the law of small numbers and representativeness.

\section{A.9 Hedonic Editing}

Hedonic editing means that people prefer some frames over others. It is the way people organize their mental accounts. For instance, "transferring assets" is an expression that emphasizes 
reallocation from one mental account to another, and can hide the fact that the first mental account was closed at loss. (Shefrin, 2000) People like to separate gains, and integrate losses. In financial markets investor who experience capital gains like to separate dividend payments, while in declining markets they can use dividends as silver linings which buffer capital losses. Thaler and Johnson (1990) study how prior gains or losses affect risk-taking. They find evidence of the house money effect (prior gains increase risk seeking), as well as break-even effect (under previous losses, gambles which offer a chance to break even seam very attractive).

\section{A.10 Law of Small Numbers}

The phenomenon is related to representativeness heuristic - people under-use base-rate information when forming their beliefs (Tversky and Kahneman, 1971). In the financial context, "we underestimate how often a good financial analyst will be wrong a few times in a row, and underestimate how often a clueless analyst will be right a few times in a row" (Rabin, 1998).

\section{A.11 Loss Aversion}

Loss aversion is a pervasive phenomenon in human decision making under risk and uncertainty, according to which people are more sensitive to losses than gains. It plays a crucial role in Prospect Theory (Tversky and Kahneman (1974), Tversky and Kahneman (1992)). A typical financial example is in investors difficulty to realize losses. Shefrin (2000) calls this phenomenon "get-evenitis," that is, people hope that markets will work in their advantage and that they will be able to terminate their investment without incurring any losses.

\section{A.12 Money Illusion}

A natural way for people to think about money is in terms of nominal rather than inflationadjusted values (Shefrin, 2000).

\section{A.13 Overconfidence}

Overconfident people are not well calibrated, in their predictions they set confidence bands overly narrow, which means they get surprised more frequently than they anticipated (Shefrin, 2000). A more general definition of overconfidence is the one by which people overestimate their own capabilities, usually with respect to capabilities of other people on average. In financial markets overconfident investors are considered those who actively trade in such a way that the difference between the stocks they buy and those they sell does not cover transaction costs (Odean, 1998). 


\section{A.14 Regret}

Regret is the emotion experienced for not having made the right decision, it is the feeling of responsibility for loss. (Shefrin, 2000) In a financial context the minimization of possible future regret plays an important role in portfolio allocation. It is also related with preference for dividends in financing consumer expenditures, because selling a stock that may rise in the future carries a huge potential for regret.

\section{A.15 Representativeness}

Representativeness bias occurs when it is required to assess the probability of an object A belonging/originating to/from a class/process B. The heuristic rule says that if object A is highly representative (highly similar to a stereotypical object) of class B, the probability of A originating from B is judged as high. And vice versa. The problem with this heuristics is that it persists even when facts, which should affect the judgment of probabilities, are introduced. For instance, they showed the representativeness is insensitive to the prior probability (base-rate frequency) of outcomes, when (uninformative) description is provided. Furthermore, it is insensitive to the sample size, when people estimate the probability related to the sample randomly drawn from a large population, based on the similarity with the population parameter. People also expect the global characteristics of a process to be present in each local part, what deviates from the chance expectations (i.e. expecting more randomness in a series of coin tosses; gambler's fallacy). The representativeness heuristic often neglects different levels of predictability, and may lead to the illusion of validity when the predicted outcome is highly representative for a given input. In this case people also neglect the phenomenon known as regression to the mean, which explains why people might overestimate the efficiency of a punishment, and underestimate the efficiency of a reward.

Representativeness heuristic is a judgment based on stereotypes (Shefrin, 2000). Representativeness is high when an observation fits the pattern (Goldberg and von Nitzsch, 2001).

Some of the most important applications of this heuristic are in predicting the market, picking stocks, choosing mutual funds, selecting money managers, and investing in initial public offerings (IPOs) and seasoned equity offerings (SEOs), (Shefrin, 2000).

A financial example is the winner-loser effect documented in (DeBondt and Thaler, 1985). Investors who use the representativeness heuristic are too optimistic about past winners, and too pessimistic about past losers. This creates a temporary mispricing (overvaluation of past winners, and undervaluation of past losers), which is eventually reversed, as the portfolio of past 
losers outperforms the market, while the winners portfolio underperforms.

Another example is a misapplication of regression to the mean, which predicts that future returns will be closer to the historical average. However, practitioners often predict that after having a long period of high returns they are more likely to be below, which is a wrong predictions in positively autocorrelated financial markets. (Shefrin, 2000). Analogously, in an experiment where subjects could ostensibly buy an asset (whose price moved randomly), Maital (1986) found that the majority expected prices to rise after a long downward trend and consequently held on them longer on average.

Misapplication of the law of large numbers to small samples is also called a gambler's fallacy, or the law of small numbers.

Representativeness can cause illusory correlation, that is, overestimation of empirical relationships. Furthermore, empirical relationships are often turned into causal relationships, which may or may not be true (Goldberg and von Nitzsch, 2001).

\section{A.16 Self-Control}

The issue of self-control and hedonic editing underlies reasons for investors preference for portfolios that feature high dividends. To finance their consumer expenditures some investors prefer dividends rather then selling assets (the heuristic "don't dip into capital"). This is due to framing/hedonic editing, because dividends are labeled as income, not as capital (Shefrin, 2000).

\section{A.17 Status Quo Bias}

People prefer status quo to changes that involve losing some goods, even when these losses are offset by some gains (Knetsch and Sinden, 1984). 


\section{References}

M. Altman. Handbook of Contemporary Behavioral Economics: Foundations and Development. M.E.Sharp, Inc., 2006.

S. Asch. Studies of independence and conformity: A minority of one against a unanimous majority. Psychological Monographs, 70, 1956.

J. T. Austin and J. B. Vancouver. Goal constructs in psychology: Structure, process, and content. The Quarterly Journal of Economics, 120(3):338-375, 1996.

N. C. Barberis and R. H. Thaler. A survey of behavioral finance. In G. M. Constantinides, M. Harris, and R. M. Stulz, editors, Handbook of the Economics of Finance, volume 1, pages 1053-1128. Elsevier, 1 edition, 2003.

S. Benartzi and R. H. Thaler. Myopic loss aversion and the equity premium puzzle. The Quarterly Journal of Economics, 110(1):73-92, 1995.

S. Benartzi and R. H. Thaler. Naive diversification strategies in defined contribution saving plans. The American Economic Review, 91(1):79-98, 2001.

D. Bernoulli. Exposition of a new theory on the measurement of risk. Econometrica, 22(1): 23-36, 1954.

J. R. Bettman, M. F. Luce, and J. W. Payne. Agent-based approach to investor's behavior and asset price fluctuation in financial markets. Journal of Consumer Research, 25(3):187-218, 1998.

Z. Bodie, A. Kane, and A. J. Marcus. Investments. McGraw Hill, 2006.

K. Boer-Sorban, A. de Bruin, and U. Kaymak. On the design of artificial stock markets. Technical Report ERS-2005-001-LIS, Erasmus Research Institute of Managemenet, 2005.

R. Bond and P. Smith. Culture and conformity: A meta-analysis of studies using asch's (1952b, 1956) line judgment task. Psychological Bulletin, 119:111-137, 1989.

C. Boone, B. D. Brabanderb, M. Carree, G. de Jong, W. van Olffen, and A. van Witteloostuijn. Locus of control and learning to cooperate in a prisoners dilemma game. Personality and Individual Differences, 32(5):929-946, 2002. 
H. Brandstätter and W. Güth. A psychological approach to individual differences in intertemporal consumption patterns. Journal of Economic Psychology, 21(5):465-479, 2000.

H. Brandstätter and W. Güth. Personality in dictator and ultimatum games. Central European Journal of Operations Research, 10(3):191-215, 2002.

T. Brenner. Agent learning representation: Advice on modelling economic learning. In L. Tesfatsion and K. L. Judd, editors, Handbook of Computational Economics, volume 2, chapter 18, pages 895-947. Elsevier, 1 edition, 2006.

J. P. Byrnes, D. C. Miller, and W. D. Schafer. Gender differences in risk taking: A meta-analysis. Psychological Bulletin, 125(3):367-383, 1999.

C. Camerer, G. Loewenstein, and D. Prelec. Neuroeconomics: How neuroscience can inform economics. Journal of Economic Literature, 43(1):9-64, 2005.

C. F. Camerer, G. Loewenstein, and M. Rabin, editors. Advances in Behavioral Economics. Princeton University Press, 2004.

N. T. Chan, B. LeBaron, and T. Poggio. Agent-based models of financial markets: A comparison with experimental markets. MIT Artificial Markets Project, 1999.

S.-H. Chen and C.-C. Liao. Behavioral finance and agent-based computational finance: toward an integrating framework. In Proceedings of 7th Joint Conference on Information Sciences, pages $1235-1238,2003$.

P. J. Cooley. A multidimensional analysis of institutional investor perception of risk. The Journal of Finance, 1977.

R. Custers and H. Aarts. Beyond priming effects: The role of positive affect and discrepancies in implicit processes of motivation and goal pursuit. European Review of Social Psychology, 16:257-300, 2005.

A. R. Damasio, B. J. Everitt, and D. Bishop. The somatic marker hypothesis and the possible functions of the prefrontal cortex. Philosophical Transactions: Biological Sciences, 351(1346), 1996.

W. F. DeBondt. A portrait of the individual investor. European Economic Review, 42(3-5): 831-844, 1998. 
W. F. DeBondt and R. H. Thaler. Does the stock market overreact? Journal of Finance, 40(3): 793-808, 1985.

V. DeMiguel, L. Garlappi, and R. Uppal. Optimal versus naive diversification: How inefficient is the $1 / \mathrm{n}$ portfolio strategy? Draft, January 2007.

J. M. Digman. Personality structure: Emergence of the five-factor model. Annual Review of Psychology, 41:417-440, 1990.

B. Donkers, B. Melenberg, and A. V. Soest. Estimating risk attitudes using lotteries: A large sample approach. Journal of Risk and Uncertainty, 22(2):165-195, 2001.

D. Dorn and G. Huberman. Talk and action: What individual investors say and what they do. Review of Finance, 9(4):437-481, 2005.

J. M. Epstein and R. Axtell. Growing Artificial Societies: Social Science from the Bottom Up. Brookings Instituion Press, 1996.

M. Fenton-O'Creevy, N. Nicholson, E. Soane, and P. Willman. Traders: Risks, decisions, and management in Financial markets. Oxford University Press, 2004.

G. M. Frankfurter and E. G. McGoun. Market efficiency or behavioral finance: The nature of the debate. The Journal of Psychology and Financial Markets, 1(4):200-210, 2000.

S. Frederick, G. Loewenstein, and T. O'Donoghue. Is time-discounting hyperbolic or subadditive? Journal of Economic Literature, 40(2):351-401, 2002.

K. French and J. Poterba. International diversification and international equity markets. The American Economic Review, 81(2):222-226, 1991.

M. Friedman. Essays in Positive Economics, chapter The Methodology of Positive Economics, pages 3-43. The University of Chicago Press, 1984.

G. Gigerenzer and D. G. Goldstein. Reasoning the fast and frugal way: Models of bounded rationality. Psychological Review, 103(4):650-669, 1996.

T. Gilovich and V. Medvec. The experience of regret: what, why, and when. Psychological Review, 102(2):379-395, 1995.

T. Gilovich, M. Kerr, and V. H. Medvec. Effect of temporal perspective on subjective confidence. Journal of Personality and Social Psychology, 64(4):552-560, 1993. 
M. Glaser and M. Weber. Overconfidence and trading volume. Journal The GENEVA Risk and Insurance Review, 32(1):1-36, 2007.

D. K. Gode and S. Sunder. llocative efficiency of markets with zero-intelligence traders: Market as a partial substitute for individual rationality. The Journal of Political Economy, 101(1): 119-137, 1993.

W. N. Goetzmann and A. Kumar. Equity portfolio diversification. NBER Working Paper Series, December 2001.

J. Goldberg and R. von Nitzsch. Behavioral Finance. John Wiley and Sons Ltd, 2001.

M. S. Haigh and J. A. List. Do professional traders exhibit myopic loss aversion? an experimental analysis. Journal of Finance, 60(1):523-534, 2005.

R. Harré. The Principles of Scientific Thinking. MacMillan, London, 1970.

L. Harris. Trading and Exchanges: Market Microstructure for Practitioners. Oxford University Press, 2003.

D. Hirshleifer. Investor psychology and asset pricing. Journal of Finance, 56(4):1533-1597, 2001.

A. O. I. Hoffmann, W. Jager, and E. J. H. V. Eije. Social simulation of stock markets: Taking it to the next level. Journal of Artificial Societies and Social Simulation, 10(2), 2007.

C. H. Hommes. Heterogeneous agent models in economics and finance. In L. Tesfatsion and K. L. Judd, editors, Handbook of Computational Economics, volume 2, chapter 23, pages 1109-1186. Elsevier, 1 edition, 2006.

G. Huberman and W. J. DeMiguel. Offering versus choice in 401(k) plans: Equity exposure and number of funds. The Journal of Finance, 61(2), 2006.

S. Jaggia and S. Thosar. Risk aversion and the investment horizon: A new perspective on the time diversification debate. The Journal of Psychology and Financial Markets, 1(3\&4): $211-215,2000$.

D. Kahneman and M. W. Riepe. Aspects of investor psychology. Journal of Portfolio Management, 24(4):52-65, 1998.

D. Kahneman and A. Tversky. Prospect theory: An analysis of decision under risk. Econometrica, 47(2):263-291, 1979. 
J. L. Knetsch and J. A. Sinden. Willingness to pay and compensation demanded: Experimental evidence of an unexpected disparity in measures of value. Quarterly Journal of Economics, 99(3):507-521, 1984.

F. H. Knight. Risk, Uncertainty, and Profit. Hart, Schaffner and Marx; Houghton Mifflin Company, 1921.

D. Laibson. Golden eggs and hyperbolic discounting. The Quarterly Journal of Economics, 112 (2):443-477, 1997.

B. LeBaron. Agent-based computational finance. In L. Tesfatsion and K. L. Judd, editors, Handbook of Computational Economics, volume 2, chapter 24, pages 1187-1233. Elsevier, 1 edition, 2006.

H. Levy and T. Post. Investments. Prentice Hall/Financial Times, 2005.

M. Levy, H. Levy, and S. Solomon. Microscopic Simulation of Financial Markets: From Investor Behavior to Market Phenomena. Academic Press, 2000.

A. W. Lo. Reconciling efficient markets with behavioral finance: The adaptive markets hypothesis. The Journal of Investment Consulting, 7(2):21-44, 2005.

A. W. Lo. Efficient markets hypothesis. In L. Blume and S. Durlauf, editors, The New Palgrave: A Dictionary of Economics, chapter 18, pages 831-880. Palgrave McMillan Ltd., 2 edition, 2007.

A. W. Lo, D. V. Repin, and B. N. Steenbarger. Fear and greed in financial markets: A clinical study of day-traders. American Economic Review, 95(2):352-359, 2005.

G. Loewenstein. Emotions in economic theory and economic behavior. The American Economic Review, 90(2):426-432, 2000.

G. Loewenstein and T. O'Donoghue. Animal spirits: Affective and deliberative processes in economic behavior. CAE Working Paper 04-14, August 2004.

G. H. Loewenstein, C. K. Hsee, E. U. Weber, and N. Welch. Risk as feelings. Psychological Bulletin, 127(2):267-286, 2001.

B. G. Malkiel. The efficient market hypothesis and its critics. The Journal of Economic Perspectives, 17(1):59-82, 2003. 
B. G. Malkiel. Reflections on the efficient market hypothesis: 30 years later. The Financial Review, 40(1):1-9, 2005.

H. Markowitz. The utility of wealth. The Journal of Political Economy, 60(2):151-158, 1952.

H. Markowitz. Portfolio selection: efficient diversification of investments. Yale University Press, 1959.

R. R. McCrae and P. T. J. Costa. The Five-factor model of personality: Theoretical perspectives, chapter Toward a new generation of personality theories: Theoretical contexts for the fivefactor model. New York, NY: Guilford, 1996.

R. Mehra and E. C. Prescott. The equity premium puzzle. Journal of Monetary Economics, 15 (2):145-161, 1985 .

B. Mellers, A. Schwartz, and D. Cooke. Judgment and decision making. Annual Review Psychology, 49:447-477, 1998.

R. Nagel. Unraveling in guessing games: An experimental study. The American Economic Review, 85(5):1313-1326, 1995.

T. Oberlechner and S. Hocking. Information sources, news, and rumors in financial markets: Insights into the foreign exchange market. Journal of Economic Psychology, 25:407-424, 2004.

T. Odean. Are investors reluctant to realize their losses? The Journal of Finance, 53(5): $17751798,1998$.

Z. Pawlak. Rough Sets: Theoretical Aspects of Reasoning about Data. Springer, 1991.

R. L. Peterson. Inside the Investor's Brain: The Power of Mind over Money. John Wiley and Sons, Inc., 2007.

M. Pidd. Tools for Thinking: Modelling in Management Science. Wiley, 2 edition, 2000.

J. Quiggin. A theory of anticipated utility. Journal of Economic Behavior and Organization, 3 (4):323-343, 1982.

M. Rabin. Psychology and economics. Journal of Economic Literature, 36(1):11-46, 1998.

D. Read. Is time-discounting hyperbolic or subadditive? Journal Journal of Risk and Uncertainty, 23(1):5-32, 2001. 
D. Read and G. Loewenstein. Diversification bias: Explaining the discrepancy in variety seeking between combined and separated choices. Journal of Experimental Psychology: Applied, 1(1): 34-49, 1995.

P. A. Samuelson. A note on measurement of utility. The Review of Economic Studies, 4(2): 155-161, 1937.

W. Samuelson and R. Zeckhauser. Status quo bias in decision making. Journal of Risk and Uncertainty, 1(1):7-59, 1988.

T. C. Schelling. Micromotives and Macrobehavior. W. W. Norton, 1978.

D. Schmeidler. Subjective probability and expected utility without additivity. Econometrica, $57(3): 571-587,1989$.

G. Shafer. A Mathematical Theory of Evidence. Princeton University Press, 1976.

W. F. Sharpe, G. J. Alexander, and J. V. Bailey. Investments. Prentice Hall, 1999.

H. Shefrin. Beyond Greed and Fear - Understanding Behavioral Finance and the Psychology of Investing. Harvard Business School Press, 2000.

H. Shefrin and M. Statman. The disposition to sell winners too early and ride losers too long: Theory and evidence. The Journal of Finance, 40(3):777-790, 1985.

H. Shefrin and R. Thaler. The behavioral life cycle hypothesis. Economic Inquiry, 26(4):609-643, 1988.

R. J. Shiller. Speculative prices and popular models. Journal of Economic Perspectives, 4(2): $55-65,1990$.

R. J. Shiller and J. Pound. Survey evidence on diffusion of interest and information among institutional investors. Journal of Economic Behavior and Organization, 12(1):47-66, 1989.

B. Shiv, G. Loewenstein, A. Bechara, H. Damasio, and A. Damasio. Investment behavior and the negative side of emotion. Psychological Science, 16(6):435-439, 2005.

A. Shleifer. Inefficient Markets: An Introduction to Behavioral Finance. Oxford University Press, 2000.

H. A. Simon. Bounded rationality and organizational learning. Organization Science, 2(1): 125-134, 1991. 
I. Simonson. The effect of purchase quantity and timing on variety-seeking behaviour. Journal of Marketing Research, 2(27):150-162, 1990.

A. Sloman. Beyond shallow models of emotion. Cognitive Processing, 2(1):177-198, 2001.

P. Slovic. Psychological study of human judgment: Implications for investment decision making. Journal of Finance, 27(4):779-799, 1972.

P. Slovic. Psychological study of human judgment: Implications for investment decision making. The Journal of Psychology and Financial Markets, 2(3):160-172, 1998.

M. Statman. Behaviorial finance: Past battles and future engagements. Financial Analysts Journal, 55(6):18-27, 1999.

H. Takahashi and T. Terano. Agent-based approach to investor's behavior and asset price fluctuation in financial markets. Journal of Artificial Societies and Social Simulation, 6(3), 2003.

L. Tesfatsion and K. Judd. Agent-based computational economics: A constructive approach to economic theory. In L. Tesfatsion and K. L. Judd, editors, Handbook of Computational Economics, volume 2, chapter 16, pages 831-880. Elsevier, 1 edition, 2006.

R. H. Thaler. Toward a positive theory of consumer choice. Journal of Economic Behavior and Organization, 1(1):39-60, 1980.

R. H. Thaler. Anomalies - the january effect. Journal of Economic Perspectives, 1(1):197-201, 1987.

R. H. Thaler. Quasi Rational Economics. Russel Sage Foundation, 1991.

R. H. Thaler. From homo economicus to homo sapiens. The Journal of Economic Perspectives, 14(1):133-141, 2000.

R. H. Thaler and E. J. Johnson. Gambling with the house money and trying to break even: The effects of prior outcomes on risky choices. Management Science, 36(6):643-660, 1990.

R. Topol. Bubbles and volatility of stock prices: Effect of mimetic contagion. The Economic Journal, 101(407):786-800, 1991.

A. Tversky and D. Kahneman. Belief in the law of small numbers. Psychological Bulletin, 76 (2):105-110, 1971. 
A. Tversky and D. Kahneman. Availability: A heuristic for judging frequency and probability. Cognitive Psychology, 5(2):207-232, 1973.

A. Tversky and D. Kahneman. Judgment under uncertainty: Heuristics and biases. Science, 185(4157):1124-1131, 1974.

A. Tversky and D. Kahneman. Advances in prospect theory: Cumulative representation of uncertainty. Journal of Risk and Uncertainty, 1992.

J. von Neumann and O. Morgenstern. Theory of Games and Economic Behavior. Princeton University Press, 1944.

L. Zadeh. Fuzzy sets. Information and Control, 8(3):338-353, 1965.

M. Zuckerman and D. M. Kuhlman. Personality and risk-taking: Common bisocial factors. Journal of Personality, 68(6):999-1029, 2000. 


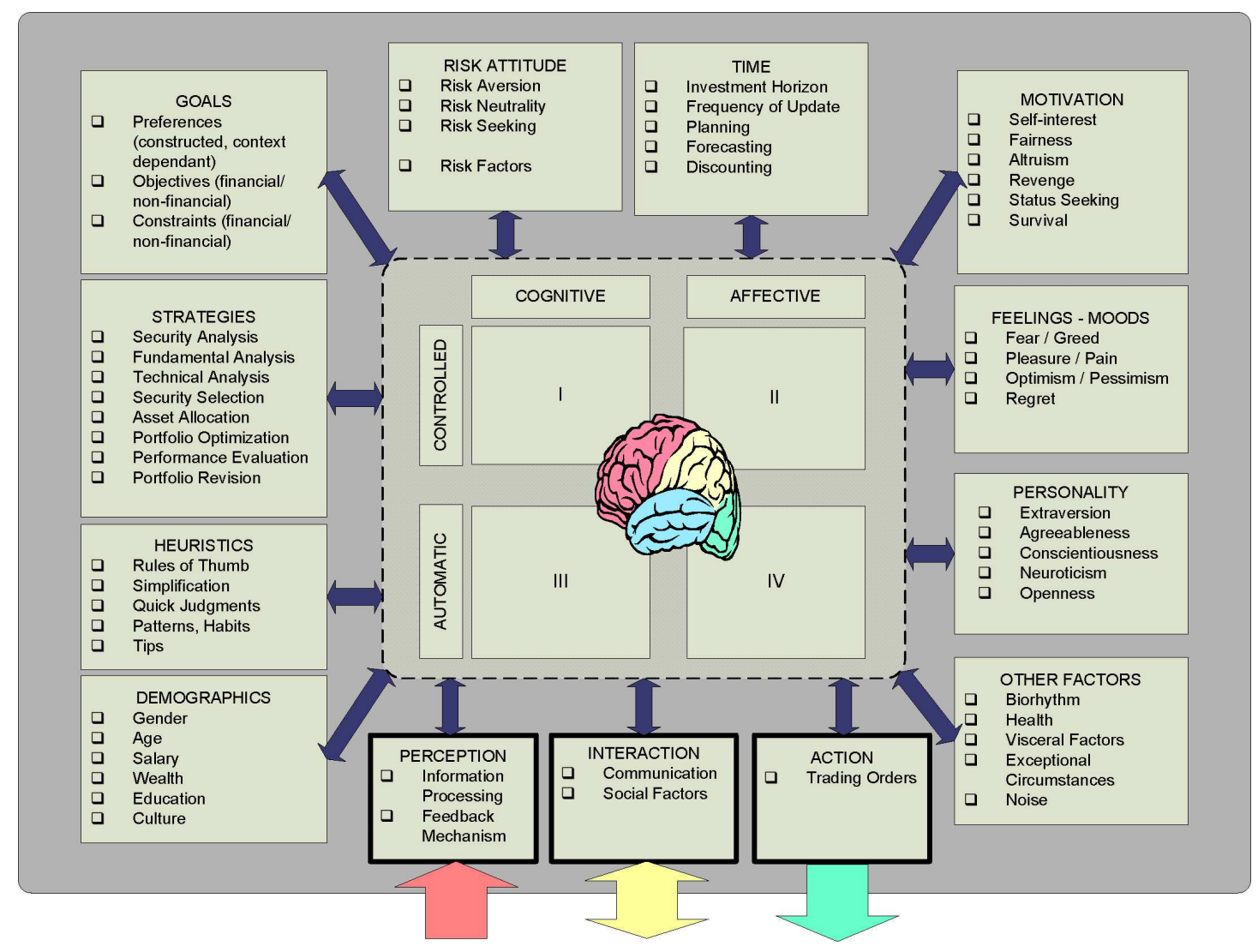

Figure 1: Cognitive model of individual investor

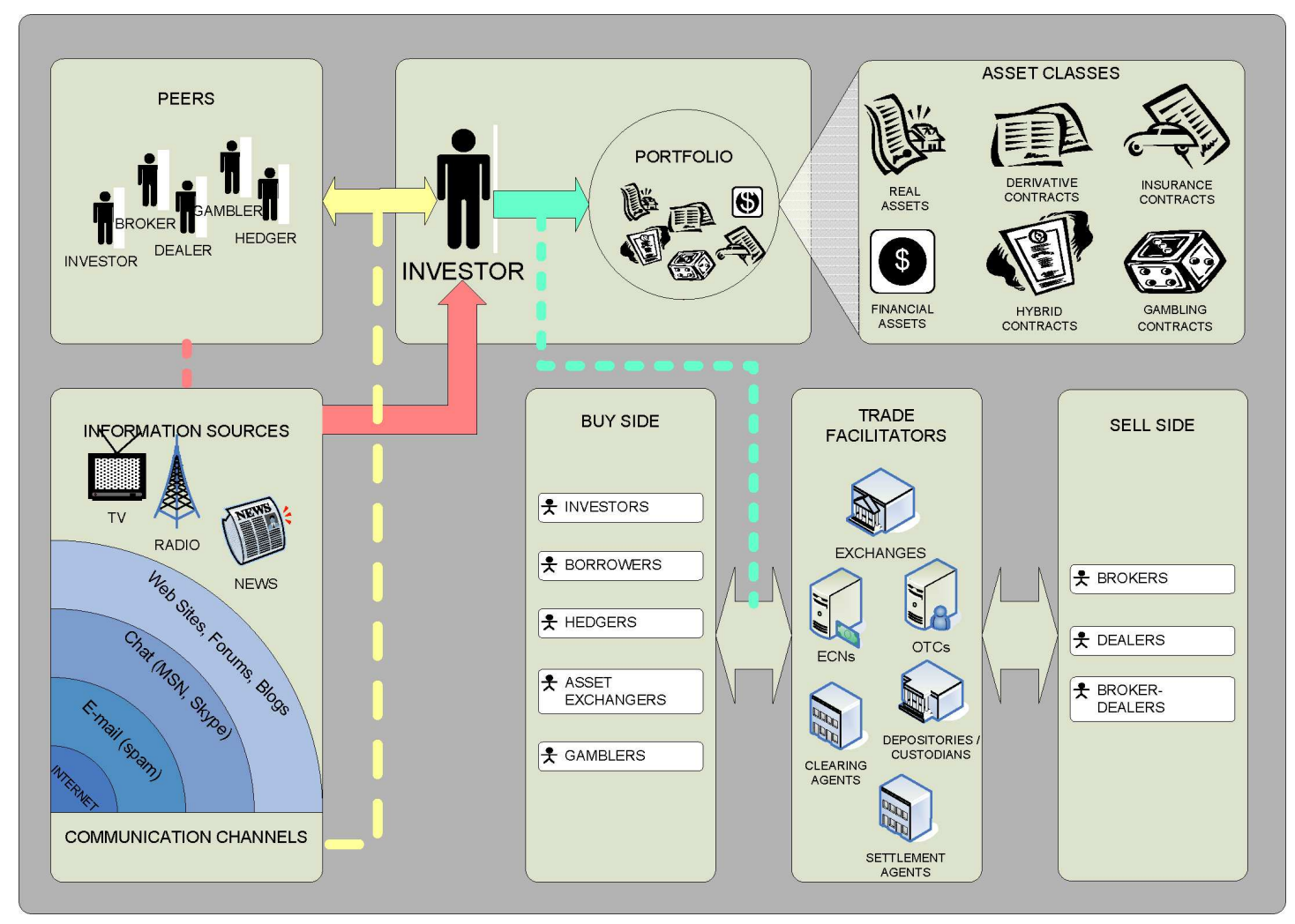

Figure 2: Investment environment 


\section{Publications in the Report Series Research ${ }^{*}$ in Management}

\section{ERIM Research Program: "Finance and Accounting"}

2008

The Inefficient Use of Macroeconomic Information in Analysts' Earnings Forecasts in Emerging Markets Gerben de Zwart and Dick van Dijk ERS-2008-007-F\&A

http://hdl.handle.net/1765/11556

Sole versus Shared Responsibility: Fraud Consultation and Auditor Judgment Anna Gold-Nöteberg, W. Robert Knechel and Philip Wallage ERS-2008-010-F\&A

http://hdl.handle.net/1765/11687

Corporate Governance and the Value of Excess Cash Holdings of Large European Firms Marc B.J. Schauten, Dick van Dijk and Jan-Paul van der Waal

ERS-2008-027-F\&A

http://hdl.handle.net/1765/12465

A Conceptual Model of Investor Behavior Milan Lovric, Uzay Kaymak and Jaap Spronk ERS-2008-030-F\&A

http://hdl.handle.net/1765/12468

A complete overview of the ERIM Report Series Research in Management: https://ep.eur.nl/handle/1765/1

ERIM Research Programs:

LIS Business Processes, Logistics and Information Systems

ORG Organizing for Performance

MKT Marketing

F\&A Finance and Accounting

STR Strategy and Entrepreneurship 